OPEN ACCESS

Edited by:

Dimitrios I. Zeugolis,

National University of Ireland Galway,

Ireland

Reviewed by:

Peter Pivonka,

Queensland University of Technology,

Australia

Janos Kanczler,

University of Southampton,

United Kingdom

*Correspondence:

Iris Ribitsch

iris.ribitsch@vetmeduni.ac.at

Specialty section:

This article was submitted to

Tissue Engineering and Regenerative

Medicine,

a section of the journal

Frontiers in Bioengineering and

Biotechnology

Received: 12 February 2020

Accepted: 27 July 2020

Published: 13 August 2020

Citation:

Ribitsch I, Baptista PM,

Lange-Consiglio A, Melotti L,

Patruno $M$, Jenner $F$

Schnabl-Feichter E, Dutton LC, Connolly DJ, van Steenbeek FG,

Dudhia J and Penning LC (2020) Large Animal Models in Regenerative Medicine and Tissue Engineering: To

Do or Not to Do.

Front. Bioeng. Biotechnol. 8:972.

doi: 10.3389/fbioe.2020.00972

\section{Large Animal Models in Regenerative Medicine and Tissue Engineering: To Do or Not to Do}

\author{
Iris Ribitsch ${ }^{1 *}$, Pedro M. Baptista ${ }^{2}$, Anna Lange-Consiglio ${ }^{3}$, Luca Melotti ${ }^{4}$, \\ Marco Patruno ${ }^{4}$, Florien Jenner ${ }^{1}$, Eva Schnabl-Feichter ${ }^{5}$, Luke C. Dutton ${ }^{6}$, \\ David J. Connolly ${ }^{5}$, Frank G. van Steenbeek ${ }^{7}$, Jayesh Dudhia ${ }^{6}$ and Louis C. Penning ${ }^{7}$ \\ ${ }^{1}$ Veterm, Department for Companion Animals and Horses, University Equine Hospital, University of Veterinary Medicine \\ Vienna, Vienna, Austria, ${ }^{2}$ Laboratory of Organ Bioengineering and Regenerative Medicine, Health Research Institute of \\ Aragon (IIS Aragon), Zaragoza, Spain, ${ }^{3}$ Department of Veterinary Medicine, Università degli Studi di Milano, Milan, Italy, \\ ${ }^{4}$ Department of Comparative Biomedicine and Food Science, University of Padua, Padua, Italy, ${ }^{5}$ Clinical Unit of Small \\ Animal Surgery, Department for Companion Animals and Horses, University of Veterinary Medicine Vienna, Vienna, Austria, \\ ${ }^{6}$ Department of Clinical Sciences and Services, Royal Veterinary College, Hertfordshire, United Kingdom, ${ }^{7}$ Department \\ of Clinical Sciences of Companion Animals, Faculty of Veterinary Medicine, Utrecht University, Utrecht, Netherlands
}

Rapid developments in Regenerative Medicine and Tissue Engineering has witnessed an increasing drive toward clinical translation of breakthrough technologies. However, the progression of promising preclinical data to achieve successful clinical market authorisation remains a bottleneck. One hurdle for progress to the clinic is the transition from small animal research to advanced preclinical studies in large animals to test safety and efficacy of products. Notwithstanding this, to draw meaningful and reliable conclusions from animal experiments it is critical that the species and disease model of choice is relevant to answer the research question as well as the clinical problem. Selecting the most appropriate animal model requires in-depth knowledge of specific species and breeds to ascertain the adequacy of the model and outcome measures that closely mirror the clinical situation. Traditional reductionist approaches in animal experiments, which often do not sufficiently reflect the studied disease, are still the norm and can result in a disconnect in outcomes observed between animal studies and clinical trials. To address these concerns a reconsideration in approach will be required. This should include a stepwise approach using in vitro and ex vivo experiments as well as in silico modeling to minimize the need for in vivo studies for screening and early development studies, followed by large animal models which more closely resemble human disease. Naturally occurring, or spontaneous diseases in large animals remain a largely untapped resource, and given the similarities in pathophysiology to humans they not only allow for studying new treatment strategies but also disease etiology and prevention. Naturally occurring disease models, particularly for longer lived large animal species, allow for studying disorders at an age when the disease is most prevalent. As these diseases are usually also a concern in the chosen veterinary species they would be beneficiaries of newly developed therapies. Improved awareness of the progress 
in animal models is mutually beneficial for animals, researchers, human and veterinary patients. In this overview we describe advantages and disadvantages of various animal models including domesticated and companion animals used in regenerative medicine and tissue engineering to provide an informed choice of disease-relevant animal models.

Keywords: large animal models, sheep, pig, horse, dog, regenerative medicine, tissue engineering, naturally occurring disease

\section{INTRODUCTION}

The use of sentient animals for research purposes is a controversial topic, which has raised public and ethical concerns and is criticized by opponents claiming that animal models often do not generate appropriate benefit with regards to their potential risks and harm and as a consequence, are often ethically not permissible. The increasing status of pets as family members and corresponding high level of veterinary care for privately owned pets further amplifies the controversy over the use of animals for research purposes.

However, animal models are still an important and, at a regulatory level, a compulsory component of translational research, which cannot yet be replaced by in vitro experiments. Although in vitro models allow for systematic, standardized analysis of various cellular, biophysical and biochemical cues in a controlled environment, without the natural variability inherent to in vivo animal models, they can only offer an abstract insight into the pathophysiology of diseases and disorders. Therefore, while animal models cannot yet be replaced, the number of animals used should be reduced to a minimum and experiments involving animals should be optimized with regard to their translatability and the welfare of the animals.

However, to date a reductionist approach often using immature laboratory species is commonly employed (Jackson et al., 2017). Small rodent animals, specifically mouse and rat, are valuable for research into mechanisms of disease and fundamental biology, but findings from such small animal models often do not translate into human clinical applications (Prabhakar, 2012; Lorbach et al., 2015). Shanks et al. impressively illustrated the translational challenges, showing the difference in bioavailability of pharmaceuticals between humans, primates, dogs and rodents (Shanks et al., 2009). However, although awareness is increasing there is still a massive disproportion between rodent studies and large animal studies.

Therefore, the European Medicines Agency (EMA), the USA Federal Food and Drug Administration (FDA) and the International Society for Stem Cell Research (ISSCR) recommend the use of large animal models to evaluate efficacy, durability, dose response, degradation and safety of advanced therapeutic medicinal products (ATMPs) $)^{1,2}$. For successful and timely translation from animal models to regulatory approval and clinical application, a step-wise development using laboratory animals for screening and early development work, followed by a large animal model such as the pig, sheep or horse which offers

\footnotetext{
${ }^{1}$ http://www.isscr.org/docs/guidelines/isscrglclinicaltrans.pdf

${ }^{2}$ https://www.fda.gov/vaccines-blood-biologics/biologics-guidances/cellulargene-therapy-guidances
}

a more realistic approach for late development and pivotal studies would be more appropriate (Hurtig et al., 2011).

Moreover, animals develop many naturally occurring (or spontaneous) diseases that are equivalent to human disease leading to the development of the "One Health One Medicine" concept which presumes that diseases in men and animals (mostly mammals) have similar aetiologies and pathophysiologies and require analogous therapeutic approaches. Hence, human and veterinary medicine can mutually benefit from research that applies a one health approach. Using large animal models with naturally occurring disease with a similar pathophysiology as in humans, allows study of not only new treatment strategies but also disease development and prevention at a relevant age. However, although using naturally occurring disease models best reflect disease complexity, standardization of disease grade and availability of sufficient clinical case numbers for recruitment into studies can be challenging.

In order to achieve the best output while following the three R's principle (to reduce, refine and replace animal models) of using the smallest possible number of animals, animal models need to be optimized to the greatest possible extent (Madden et al., 2012). They require careful selection and design to ensure they are fitfor-purpose and address both optimal predictive validity, as well as ethical, animal-welfare and societal considerations. Species, anatomic, physiologic, biomechanical aspects and their clinical relevance need to be considered.

Furthermore, knowledge regarding the epidemiology and natural history of diseases in different animal species, disease similarities to humans, availability of diagnostics, treatment options, and outcome measures as well as criteria defining species specific quality of life and functional parameters is important but still scarce in the scientific community. Other important considerations in using large animal models include availability, handling and economic concerns.

To optimize scientific output and translational potential with animal welfare needs, tight cooperation between basic science, human and veterinary medicine is necessary. The veterinary academic environment offers unique expertise to make that goal attainable to the highest standards. This includes the veterinary knowledge required to make a rational decision for the choice of animal model rather than being based on in-house availability.

There are several research groups which have a track record of developing preclinical large animal models, some of which have managed to translate their research into clinical applications (Kang et al., 2010, 2013; Mcilwraith et al., 2011, 2012; Godwin et al., 2012; Smith et al., 2013; Bach et al., 2017; Whitehouse et al., 2017; Goldberg et al., 2018; Tellegen et al., 2018; Broeckx et al., 2019; Tellegen et al., 2019). This - by no means 
exhaustive - list clearly demonstrates the collective efforts of the veterinary community to provide large animal models to be used in translational projects.

However, yet it is still often argued, that translational studies using large animal models are rare because they are complex, time-consuming, technically demanding, slow, and usually not suitable for mechanistic investigations. Nevertheless, because large animals better reflect the human body conformation and pathophysiology of certain naturally occurring diseases than rodent models, these studies are essential justifying the challenges and costs. Unfortunately, the added value of the clinical relevance of large animal models is often not appreciated by reviewers of manuscripts and grant applications are assigned low scores on the basis of lack of mechanistic insights and insufficient conceptual novelty. However, for a successful translation of tissue engineering and regenerative medicine research into clinical therapies, it is critical that this misperception is corrected.

It is the authors' hope that this review, which introduces different large animal models, their naturally occurring diseases and their specificities, may stimulate biomedical researchers to look for the very best model possible for their specific research question and that it will encourage interdisciplinary cooperation to optimize the choice of disease-relevant animal models in the future. Deciding which animal model should be used in a particular study is first and foremost dependent on defining the specific question that needs to be answered. Only then can the pertinent benefits and drawbacks of individual models be considered and a decision made.
In this review, we focus on horses, sheep, dogs, cats and pigs as the most frequently used large animal models in research and do not include primates due to the ethical dimension and limited indications, which require their specific use. Using animals which are so similar to humans, raises serious ethical concerns. Therefore, the use of non-human primates is closely monitored and strictly regulated and much has been done to specifically safeguard these animals. The use of great apes has been completely prohibited. As long as non-human primates are used for medical research, the European Commission strongly advocates the "3Rs principle," now a legal obligation embedded in the EU legislation to: Replace non-human primates with viable alternatives whenever feasible, Reduce the use of nonhuman primates and Refine scientific procedures and the care and treatment of the animals. Even phasing-out the use of nonhuman primates in Europe is discussed ${ }^{3}$.

\section{WHY THE CHOICE OF ANIMAL MODELS IS CRUCIAL}

The most obvious and demonstrative reason why the choice of animal models is crucial, are gross anatomic differences between the human and different animals and even between animals of different species (Figure 1). These differences imply that the same anatomic structures may have a different function and are subjected to different biomechanical strains. Table $\mathbf{1}$

${ }^{3}$ https://ec.europa.eu/health/sites/health/files/scientific_committees/scheer/docs/ scheer_o_004.pdf
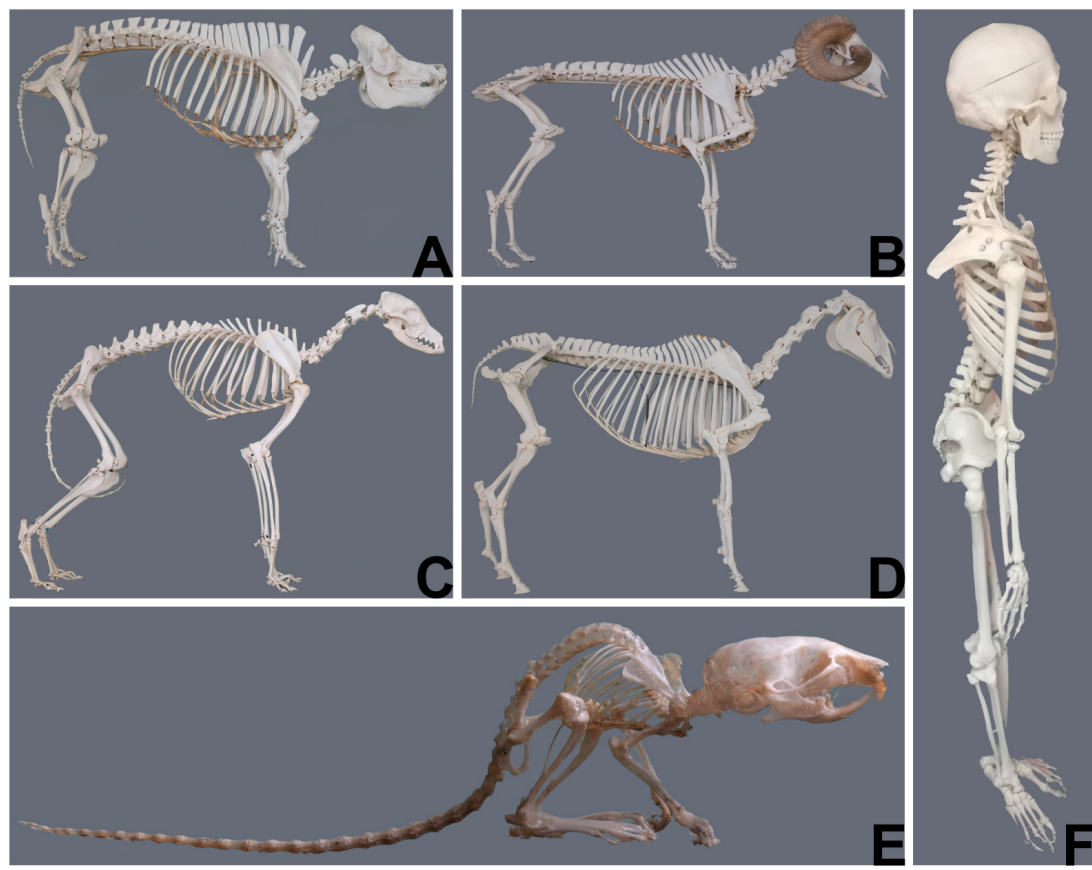

FIGURE 1 | Gross anatomical differences between animals of different species (courtesy of Niklas Dresen, Institute of veterinary anatomy, University Leipzig) and the human (courtesy of Elfriede Cremer, Bernhard Cremer and Elisabeth Schieder). (A) Pig; (B) Sheep; (C) Dog; (D) Horse; (E) Mouse; (F) Human. 
TABLE 1 | Comparison of physiologic and biomechanical parameters of different model animals.

\begin{tabular}{|c|c|c|c|c|c|c|c|c|c|}
\hline Species & Mouse (C57BL/6) & Rat & Rabbit & Canine & Mini-Pig & Sheep & Goat & Horse & Human \\
\hline Body temperature (in ${ }^{\circ}$ Celsius) & $36.5-37.3^{\circ} \mathrm{C}$ & $37.5-39.5$ & $38.0-39.5$ & $38.0-39$ & $38.3-38.8$ & $38.5-39.5$ & $38.3-39.0$ & $37.5-38.0$ & $36.5-37.3$ \\
\hline Heartrate (beats per minute) & $491-626$ & $250-450$ & $150-300$ & $60-160$ & $68-72$ & $60-80$ & $60-80$ & $28-40$ & $60-80$ \\
\hline Respiration rate per minute & 272 & $70-120$ & $35-100$ & $15-30$ & $14-18$ & $16-30$ & $10-30$ & $10-14$ & $12-20$ \\
\hline $\begin{array}{l}\text { Cartilage thickness medial femoral } \\
\text { condyle (in mm) }\end{array}$ & 0.1 & & 0.3 & $0,6-1.3$ & 1.5 & $0.7-1.7$ & $0.7-1.5$ & 1.75 & 2.35 \\
\hline Critical size cartilage defect (in mm) & & 1.4 & 3 & 4 & 6 & 7 & 7 & 9 & 10 \\
\hline $\begin{array}{l}\text { Subchondral bone plate thickness } \\
\text { medial femoral condyle (in mm) }\end{array}$ & & & $0.4-0.5$ & & & 0.7 & 0.3 & 0.7 & $0.2-0.5$ \\
\hline $\begin{array}{l}\text { Anterior cruciate ligament length } \\
\text { (in } \mathrm{mm} \text { ) }\end{array}$ & & & 10.6 & 21.2 & 37.0 & 31.77 & & & 37.78 \\
\hline $\begin{array}{l}\text { Anterior cruciate ligament diameter } \\
\text { (in } \mathrm{mm} \text { ) }\end{array}$ & & & 4.84 & 5.45 & 10.86 & 9.27 & & & 12.73 \\
\hline $\begin{array}{l}\text { Posterior cruciate ligament length } \\
\text { (in } \mathrm{mm} \text { ) }\end{array}$ & & & 10.0 & 22.8 & 39.68 & 37.03 & & & 40.30 \\
\hline $\begin{array}{l}\text { Posterior cruciate ligament diameter } \\
\text { (in } \mathrm{mm} \text { ) }\end{array}$ & & & 4.34 & 5.33 & 8.2 & 6.67 & & & 14.23 \\
\hline Medial Meniscus length (in mm) & & & 9.2 & 16.83 & 25.32 & 25.63 & & & 39.8 \\
\hline Lateral meniscus length (in mm) & & & 10.0 & 16.3 & 25.60 & 26.03 & & & 33.28 \\
\hline $\begin{array}{l}\text { Range of motion - knee joint extension } \\
\left(\text { in }^{\circ} \text { ) }\right.\end{array}$ & & & 22 & 34 & 42 & 40 & 45 & & 2.5 \\
\hline $\begin{array}{l}\text { Range of motion - knee joint extension } \\
\left(\text { in }^{\circ} \text { ) }\right.\end{array}$ & & & 161 & 160 & 144 & 146.7 & 145.5 & & 137.5 \\
\hline $\begin{array}{l}\text { Age of skeletal maturity (age until } \\
\text { growths plates remain open) }\end{array}$ & $\begin{array}{l}3-6 \text { months } \\
\text { (growths plates } \\
\text { remain open } \\
\text { life-long) }\end{array}$ & & $16-39$ weeks & $12-24$ weeks & $42-52$ weeks & $36-48$ months & $36-48$ months & $60-72$ months & $18-22$ years \\
\hline Weight at skeletal maturity in $\mathrm{kg}$ & $20-40 \mathrm{~g}$ & $0.25-0.55$ & $3-4$ & $1-30$ & $20-40$ & $40-70$ & $40-70$ & $450-500$ & $60-90$ \\
\hline Life span in years & 2 & $2.5-3.5$ & & $10-15$ & 15 & $10-12$ & $15-18$ & 30 & $70-80$ \\
\hline
\end{tabular}

Table modified from Tankersley et al (1994): Campen et al (2005), Frisbie et al. (2006): Baumgartner et al. (2009), Chu et al. (2010): Proffen et al. (2012), Maher et al. (2015). Moran et al. (2016) and https: //www.jax.org/news-and-insights/jax-blog/2017/november/when-are-mice-considered-old\# and https://www.jax.org/jax-mice-and-services/strain-data-sheet-pages/body-weight-chart-000664. 
illustrates differences of different animals to emphasize the importance of correct model selection with respect to species' physiologic aspects.

\section{Age Matters}

Age should be an important consideration in the choice of any animal model independent of the species used (Jackson et al., 2017). For practical and organizational reasons animal trials are often carried out in juvenile or neonatal animals. However, differences in the healing potential and therefore the healing response between juvenile and adult animals can bias the outcome of such trials (Namba et al., 1998; Beredjiklian et al., 2003; Conboy et al., 2005; Favata et al., 2006; Bos et al., 2008; Ansorge et al., 2012; Connizzo et al., 2013; Mienaltowski et al., 2016; Van Weeren and Back, 2016; Jackson et al., 2017). The use of skeletally mature animals of an appropriate age (Table 1) to mimic adult disease and healing potential is therefore a critical consideration for optimal study design. To truly reflect human age-related disease, the animals used should be of comparable age. Ideally old animals would be used to study age-related diseases as for instance senile osteoporosis. However, the use of elderly compared to immature or young adult animals requires specific considerations, as aged animals are more difficult to procure and may suffer from comorbidities. Hence, potential animal loss due to other diseases needs to be accounted for in the study design and financial planning. Furthermore, the predisposition for age-related diseases varies between species.

\section{Naturally Occurring and Generated Models of Genetic Disease}

Many naturally occurring genetic diseases have been identified in companion and farm animals which are often caused by a mutation in an orthologous gene and lead to a comparable clinical phenotype as observed in human patients, including the pathological alterations at the biochemical and cellular levels (Lairmore and Khanna, 2014; Kol et al., 2015). Most of these animal models are associated with congenital heart disease, lysosomal storage disease, hemophilia, muscular dystrophies, neurological disorders, immunodeficiencies and dwarfism (Lairmore and Khanna, 2014). Information about these naturally occurring genetic diseases in animals was compiled in a comprehensive database - Online Mendelian Inheritance in Animal - created by Prof. Frank Nicholas at The University of Sydney and Australian National Genomic Information Service ${ }^{4}$.

\section{Naturally Occurring and Generated Models of Musculoskeletal Disease}

Osteoarthritis (OA) is a heterogeneous disease for which no single animal model perfectly recapitulates the complex etiology and clinical manifestations of the human disease (Aigner et al., 2010; Cohen-Solal et al., 2012; Little and Zaki, 2012; Mccoy, 2015). Currently available OA models are generally grouped into spontaneous, or surgically induced models. Spontaneous models include naturally occurring disease or

${ }^{4}$ https://omia.org/home/ genetically manipulated models, whereas surgically induced models employ (i) destabilization of the joint such as partial or total meniscectomy, meniscal tear, anterior cruciate ligament or posterior cruciate ligament transection, medial and/or lateral collateral ligament transection or osteotomy (ii) physical defects of the articular cartilage such as creation of articular grooves, (iii) impact trauma including transarticular impact, and intra-articular osteochondral fragmentation (iv) chemically induced lesions using intra-articular injection of monosodium iodoacetate, collagenase, carrageenan or Freund adjuvant (Bentley, 1975; Little and Zaki, 2012; Lampropoulou-Adamidou et al., 2014; Mccoy, 2015). Spontaneous models that develop progressive and chronic disease are likely to more closely mimic idiopathic OA. However, these models take longer to develop and tend to be more variable with respect to outcome measures (Vincent et al., 2012; Teeple et al., 2013; Lampropoulou-Adamidou et al., 2014; Mccoy, 2015).

Surgical models have the advantage of repeatability and reproducibility as well as rapid onset and progression (Lampropoulou-Adamidou et al., 2014), but for that reason are less ideal models of spontaneous $\mathrm{OA}$ and are often regarded as posttraumatic (secondary) OA (Bendele, 2001; Little and Hunter, 2013; Teeple et al., 2013; Mccoy, 2015).

The validity of chemically induced models for OA has been questioned (Poole et al., 2010; Teeple et al., 2013) due to the resulting widespread cell death and rapid joint destruction, which are not considered typical for either spontaneous or posttraumatic OA (Little and Zaki, 2012).

Animal models are further widely used in osteoporosis research. They include, among others, models for disuse induced osteoporosis, glucocorticoid-induced osteoporosis and postmenopausal osteoporosis. The most popular animal models of postmenopausal osteoporosis are those generated in the mouse, rat, sheep, and nonhuman primates by ovariectomy (Iwaniec, 2008).

The choice of the animal models differ markedly, depending on the objectives of the study. It has to be noted that rodents for example are of limited value for investigating intra-cortical bone remodeling, because they lack true Haversian cortical bone remodeling under physiological conditions due to their small weight (Baron et al., 1984; Lelovas et al., 2008; Iwaniec, 2008). Larger animals such as dogs are more appropriate for these studies because, similar to humans, dogs have well-developed Haversian remodeling (Iwaniec, 2008).

\section{Challenges of Translating Results From Animal Models to Human Patients - An Example}

To date, animal models of human asthma have included: Drosophila, rats, guinea pigs, cats, dogs, pigs, cattle, sheep, horses and primates, but the most widely used model is the mouse (Zosky and Sly, 2007; Kirschvink and Reinhold, 2008; Shapiro, 2008; Blume and Davies, 2013). The mouse is a useful model due to the availability of specific probes and reagents for studying allergic outcomes, such as cellular and humoral responses, and the good adaptability for genetic 
manipulation (Shapiro, 2008; Bonamichi-Santos et al., 2015). Nevertheless, this model has some limitations for translational medicine mainly related to the anatomical and physiological differences with respect to man. Obviously, the lung and bronchial tree, total lung capacity (6 liter for man vs. $1 \mathrm{ml}$ for mouse), and the blood-gas barrier thickness $(0.62 \mu \mathrm{m}$ vs. $0.32 \mu \mathrm{m}$ ) are much smaller than in man and the bronchial artery supplies the entire lung in man but is absent in the pleura, septa and alveoli in mice. In addition, the respiratory rate, or beats per minute $(10-14$ vs. $250-350)$, is very different in people and mice. Moreover, the mouse lacks sub-mucosal glands and has limited airway smooth muscles compared to man (Lange-Consiglio et al., 2019). In view of these important differences, the pre-clinical results obtained when using a mouse model for asthma should be interpreted with care. Furthermore, the mouse does not have natural inflammatory or allergic pulmonary pathologies, so airway inflammation is usually induced by exposure to ovalbumin (OVA) or other aeroallergens. In contrast to naturally occurring human asthma, which is a chronic disease characterized by persistent inflammation and remodeling due to intermittent or continuous inhalation exposure to allergens resulting in chronic eosinophilic/neutrophilic inflammation (Aun et al., 2017; Bullone and Lavoie, 2019), the mouse model shows more acute ( $<3$ months) inflammation and no remodeling. To circumvent this problem, systemic sensitization protocols and repeated exposures to allergens have been tried but the results obtained from different routes of systemic sensitization (subcutaneous injection, intraperitoneal injection or intranasal inhalation) and different allergens (OVA, fungi, Ascaris antigens, house dust mite, cockroach extracts), used alone or in combination, are difficult to compare and to interpret (Aun et al., 2017). For example, in the mouse the induced inflammation profile, although dependent on the antigen, is mainly Th2, mirroring disease in only a subsection of human asthmatics who are Th2 and/or Th1/Th17 (Douwes et al., 2002; Woodruff et al., 2009). Another criticism of the mouse model is that OVA does not induce asthma in human patients and the sensitization routes do not mimic the routes of exposure to allergens in human asthma (Aun et al., 2017). Hence, differences in the results may be due to the different types of allergens and sensitization routes.

An appropriate animal model for translational studies should mimic the pathological changes associated with human asthma and reflect the environmental factors that determine the evolution of human asthma.

\section{HORSES AS ANIMAL MODELS}

\section{General Considerations}

Horses (equus caballus) are a well-accepted, well-established and clinically relevant animal model particularly for musculoskeletal disease, which is of major interest in regenerative medicine.

An important aspect of clinical research is the precise demonstration of the initial injury, the disease progress, outcome and follow up. The validated applicability of advanced diagnostic methodologies in horses such as arthroscopy and MRI (together with scoring approaches) (Brittberg and Winalski, 2003; Marlovits et al., 2006), ultrasound, radiographs, CT and scintigraphy, has made the horse a popular model for which non-terminal studies with thorough evaluation and monitoring are possible. Also, second-look arthroscopy and serial sampling are feasible. Moreover, the large size of horses allows for the creation of critical size defects or multiple defects and offers a high amount of material that can be sampled for analysis. This enables large and comprehensive studies which may not be possible in smaller animals. Together with well-established histologic scoring (Mcilwraith et al., 2010) and pain scores (Price et al., 2003; Graubner et al., 2011; Dalla Costa et al., 2014; Gleerup et al., 2015) or assessment of other clinical parameters for horses these methods facilitate comparability of diagnosis, follow-up and results. Controlled postoperative exercise programs and rehabilitation protocols using e.g., treadmills and horse walkers further support standardization of the results. A broad offer of modern methods to further objectify outcome measures became available including gait kinematics (e.g., lameness locators) and/or kinetics using force plate/ground reaction force analysis.

Also the lack of traceability of cells injected for cell therapies could be overcome to a certain extent by using either super paramagnetic iron oxide particle (SPIO) for MRI (Delling et al., 2015a,b; Julke et al., 2015; Berner et al., 2016; Burk et al., 2016) or nuclear labeled (Technetium 99M, GFP, Indium 111) cells for scintigraphic tracing (Sole et al., 2012, 2013; Becerra et al., 2013; Trela et al., 2014; Dudhia et al., 2015; Spriet et al., 2015; Espinosa et al., 2016; Geburek et al., 2016; Scharf et al., 2016).

Some disadvantages of using the horse as a model include high costs of animal of animal purchase, maintenance/handling as well as ethical concerns and lower acceptance of the horse as an experimental animal compared to small animal studies by the lay public. In addition, some key parameters building the framework used in studies applying Omics approaches are not well enough researched in horses yet. A restrictive annotation status and availability of equine specific antibodies, molecular tools and markers are limiting factors. A major challenge when using horses is that their weight precludes non-weight-bearing investigations postoperatively. Significant limitations may arise regarding biomechanical strains, which far exceed those considered physiologic in humans and other animal models, which could render the stabilization of injured structures, transplants and/or sutures ineffective. Therefore, horses are a less amenable model for meniscus or bone repair. Nonetheless, these are major challenges in equine patients and several different attempts have been made or are envisaged to support healing of these structures by regenerative medicine approaches (Fox et al., 2010; Milner et al., 2011; Ferris et al., 2012; Kisiday et al., 2012; Mcduffee et al., 2012; Seo et al., 2014; Warnock et al., 2014; Govoni, 2015; Yu et al., 2015; Gonzalez-Fernandez et al., 2016) which may also hold valuable preclinical results for human medicine. For example, hyperextension of the stifle joint was found to lead to pathologic levels of forces and injury in the cranial horn of the equine medial meniscus, analogous to observations 
in the human posterior medial horn upon hyperflexion (Drosos and Pozo, 2004).

\section{Tendinopathy}

Horses commonly suffer from naturally occurring tendon injuries (tendinopathy) and degenerative joint disease (osteoarthritis - OA) with similar pathophysiology to the human in terms of etiology and risk factors, which include over-exercise, age and genetic factors (Goodship et al., 1994; Patterson-Kane and Firth, 2009; Mcilwraith et al., 2012; Voleti et al., 2012; Smith et al., 2014; Andarawis-Puri et al., 2015). As athletic individuals, horses incur idiopathic primary or sports related injuries to tendon and joint related tissue.

An example is the equine superficial digital flexor tendon (SDFT) which performs a similar function to the human Achilles tendon during high-speed locomotion. In both species, their respective tendons are one of the most frequently injured (Jarvinen et al., 2005; Thorpe et al., 2010) with age and participation in sports as key risk factors. The SDFT supports the metacarpophalangeal (MCP) joint and functions as an energy storing elastic tissue to enable efficient locomotion. During high-speed locomotion the SDFT can experience strains of $16 \%$ as the MCP joint hyperextends. These strains are within the functional limit of the SDFT at which failure can occur (Richardson et al., 2007). The Achilles tendon can experience strains of up to $8 \%$ allowing as much as $34 \%$ of the total work performed by the calf muscles to be stored in the Achilles (Fukashiro et al., 1995).

Acute and chronic Achilles tendon pathology is estimated to be responsible for as many as 50\% of all sports-related injuries in humans (Fukashiro et al., 1995; Maffulli, 1999; Jarvinen et al., 2005). The incidence of SDFT tendinitis in horses is reported to be as high as $8-43 \%$ (Dowling et al., 2000). Injuries in both often manifest within the body of the tendon as core lesions, which heal by the formation of fibrous scar tissue. This scar tissue is biomechanically inferior with significantly reduced elasticity which leads to a high risk of re-injury (Smith, 2008). It is therefore essential that repair strategies are aimed at restoring function by achieving scar-free healing for which regenerative medicine holds great potential. Studies in the horse to test and improve cell and cell free therapies for tendon regeneration (Smith et al., 2003; Pacini et al., 2007; Richardson et al., 2007; Schnabel et al., 2007; Fortier and Smith, 2008; Lacitignola et al., 2008; Smith, 2008; Godwin et al., 2012; Marfe et al., 2012; Carvalho Ade et al., 2013; Renzi et al., 2013; Smith et al., 2013; Van Loon et al., 2014; Geburek et al., 2015; Muttini et al., 2015) could serve as preclinical data for human medicine.

However, due to the challenges of standardization of disease grade and availability of sufficient clinical case numbers for recruitment of horses with naturally occurring disease, a number of induced equine models have been developed to investigate both tendon and joint disease.

Several surgically induced tendon injury models have been developed to try to achieve a standard lesion size, anatomical location and the ensuing inflammatory response as well as time to treatment (Guest et al., 2008; Schramme et al., 2010;
Caniglia et al., 2012; Cadby et al., 2013). While most of these are aimed at partial or full transection of the tendon, the mechanically induced model described by Schramme et al. (2010) mimics a typical tendon core lesion of spontaneous disease with similarities in healing characteristics (Cadby et al., 2013). In contrast, collagenase induced tendon injury models which attempt to mimic core lesions (Williams et al., 1984; Nixon et al., 2008; Moraes et al., 2009; Schnabel et al., 2009; Crovace et al., 2010; Karlin et al., 2011; Watts et al., 2011, 2012; Carvalho Ade et al., 2013) lead to a strong inflammatory response and are difficult to standardize with respect to location, size, shape and volume due to leakage of collagenase through the injection sites and uncontrollable diffusion from the center of the tendon (Schramme et al., 2010).

\section{Cartilage Injuries and Osteoarthritis}

Another example to illustrate "what the horse can tell the human" is Osteoarthritis, a degenerative joint disease characterized by progressive loss of articular cartilage. Adult articular cartilage has limited capacity for repair and regeneration (Kim et al., 1991). Any disruption of the superficial zone, or injury to the chondrocytes that maintain the cartilage matrix and zonal architecture, affects the load-distribution of the viscoelastic hyaline cartilage and may ultimately culminate in degenerative joint disease (Rolauffs et al., 2010). OA of the knee and hip joints is one of the most commonly diagnosed diseases in human general practice with 52 million people $(=22.7 \%$ of adults older than 18 years) in the United States and an estimated $30-40$ million Europeans suffering from arthritis of one or more joints (Cheng et al., 2012; Johnson and Hunter, 2014). With age and obesity as key risk factors the prevalence of $\mathrm{OA}$ is expected to double by the year 2020 (Johnson and Hunter, 2014). As currently no proven disease-modifying therapy capable of restoring damaged articular cartilage and function of the joint is available, there is an increasing demand for novel, safe and effective treatments, which regenerative medical research could offer. In equids as for human patients, there is an unmet need for early diagnosis and effective treatments that allow return to full performance (Mccoy, 2015). In horses OA constitutes the main cause of chronic lameness with an incidence of chronic degenerative joint disease in elderly horses of up to $83.5 \%$. Interestingly, not only is the pathophysiology of equine OA similar to the human but also the thickness of the knee cartilage is similar to the human (Frisbie et al., 2006; Malda et al., 2012). These similarities support the horse as relevant model for studies on naturally occurring OA.

A number of surgically induced equine models of articular cartilage degeneration and healing have been developed which were reviewed by Mcilwraith et al. (2011). As in humans, the major aims of OA research are to achieve resurfacing of the damaged cartilage with biomechanically resilience and acceptable pain control. However, for any studies on cartilage repair it is important that the duration should be at least 8 to 12 months, as failure at long-term follow-up is a common outcome in human and equine clinical trials even if short-term results look promising in animal models (Mcilwraith et al., 2011). 


\section{Asthma}

Horses, analogous to humans, commonly suffer from asthma. Asthma is a chronic inflammatory disease characterized by airway hyper-responsiveness and airway remodeling due to increased mucus production, epithelial fibrosis, hypertrophy and hyperplasia of airways smooth muscles, and gland enlargement (Shinagawa and Kojima, 2003). This remodeling can induce irreversible obstruction of airways and may be a consequence of chronic tissue inflammation and altered repair processes. Since function and structure are closely related, the hypothesis is that remodeling leads to loss of airway and lung function (Bullone and Lavoie, 2019).

Around 300 million people worldwide (both adults and children) suffer from asthma and hence the societal impact is high $^{5}$. The standard therapy is based on corticosteroid administration to reduce airway obstruction thus improving quality of life. However, about $20 \%$ of people are corticosteroid resistant and do not respond to therapy (Panettieri, 2016). Corticosteroid therapy is reparative and not regenerative and does not counteract remodeling. Better therapies may be derived from a regenerative approach to asthma-induced pathology.

The gold standard species for studies into human asthma would be human patients, but such studies are ethically impossible, because of the large number of patients requiring repeated biopsies to understand the causes of remodeling. Therefore, although requiring ethical authorizations, animal models are essential to advance understanding of the disease.

Severe equine asthma (SEA), which occurs spontaneously in horses (Herszberg et al., 2006; Williams and Roman, 2016), shares many features with human asthma. The horse has potential to be a good animal model with similar lung anatomy to man. SEA shares many features with human asthma: lower airway inflammation, completely reversible airflow obstruction, bronchial hyperresponsiveness, increased respiratory efforts at rest, coughing and exercise intolerance (Bullone and Lavoie, 2015; Couetil et al., 2007). This condition is spontaneously triggered by exposure to environmental antigens present in horse housing, similar to exposure in man and it can become incurable like chronic asthma in people. Up to $10-15 \%$ of adult horses suffer from SEA (Hotchkiss et al., 2007) with a Th-2 predominant cytokine profile (increase of IL-4), as described in human asthma (Lavoie et al., 2001; KlukowskaRotzler et al., 2012), and decrease of Th-1 profile (decrease of interferon- $\gamma$ ). The predominant cell type in bronchoalveolar lavage fluid (BALF) found in horses may be different to humans depending on the severity of asthma: horses with severe and late-onset asthma have neutrophilic inflammation (Panettieri, 2016) as demonstrated in some people (Cosmi et al., 2016), while increased eosinophils are frequently detected in milder forms of equine asthma (Couetil et al., 2007). As in people with neutrophilic asthma, horses with SEA can show an increase in Th-17 expression (Debrue et al., 2005; Cosmi et al., 2016).

In a good animal model, homology of genes regulating immune function is essential and the horse shares higher

${ }^{5}$ https://goldcopd.org/wp-content/uploads/2016/04/GOLD-2018-WMS.pdf

homology with man for IL2, IL23, and IL17, compared to the mouse (Tompkins et al., 2010; Lange-Consiglio et al., 2019). However, the most interesting aspect of the horse as a model to study asthma is airway remodeling, although this is less marked and involves the bronchial tree more peripherally than in man (Bullone and Lavoie, 2019). The remodeling can be completely reversed by appropriate corticosteroid treatment in both human patients and horses (Bullone and Lavoie, 2019) and sequential biopsies can be collected from the same standing sedated horse without the imperative to sacrifice the animal as compared to the mouse (Leclere et al., 2011).

\section{Additional Considerations Regarding Horses}

In horses' wounds on the distal limbs show delayed healing compared to wounds located on the upper body.

Reasons for this are not fully understood. However, differences in the rate of epithelization and wound contraction, inefficient inflammatory response (resulting in chronic inflammation and hence impaired formation of healthy granulation tissue), imbalance in collagen homeostasis, profibrotic environment, tissue hypoxia and inappropriate cell apoptosis are discussed as contributing factors (Provost, 2019).

Interestingly ponies heal better and faster than horses, with ponies yielding a quicker and more intense inflammatory response and an improved resistance to infection as compared to horses (Provost, 2019). Some of the most important advantages and disadvantages of using horses as model animals are summarized in Table 2.

Another challenge of using horses as animal models, particularly for orthopedic disease, is so called supporting limb laminitis (SLL). Laminitis is a disorder of the tissue suspensory apparatus which suspends the distal phalanx to the inside of the

TABLE 2 | Advantages and disadvantages of the horse as a model.

\section{Advantages}

Largest of the models: Multiple large (critical size) defects and serial sampling possible Functional correspondence of equine SDFT and human Achilles tendon

Thickness of the knee cartilage is similar to the human

Imaging plus validated scoring approaches

Arthroscopy (also second look) plus validated scoring approaches

Controlled postoperative exercise programs and rehabilitation using treadmills and horse walkers to support standardization are well established

Well characterized temporal pattern of healing

Equine aging well documented

Clinical need - naturally occurring disease

\section{Disadvantages}

Ethical concerns - companion animals

Different breeds, not usually purpose-bred for research

Costs- Special facilities needed for housing, surgery, imaging, necropsy, etc.

Non-weight-bearing postoperatively is not feasible Restrictive annotation status and availability of equine specific antibodies, molecular tools and markers

Weight - biomechanical strains, which far exceed those considered physiologic in humans 
horse's hoof wall. SLL of the contralateral or supporting limb occurs when horses are forced to bear weight predominantly unilaterally (with the supporting limb) for prolonged periods, due to a severe, unilateral lameness. Mechanical loading or overloading of the supporting limb is the primary factor in its pathogenesis (Baxter and Morrison, 2008; Orsini, 2012).

\section{SHEEP AS ANIMAL MODELS}

\section{General Considerations}

Domestic sheep (Ovis aries) provide unique opportunities in research as an experimental and pre-clinical animal model (Hems and Glasby, 1992; Glasby et al., 1993; Al Abri et al., 2014) because of their availability, low costs and acceptance by the society as a research animal (Diogo et al., 2017). Sheep are docile, easy to handle and relatively inexpensive with respect to housing and feeding. Their size (50-90 kgs) is more similar to humans than small animal models, lending themselves to repeated sampling from different anatomical structures over an extended period. Their size is ideal for clinical imaging modalities designed for humans such as MRI or CT (which are limited with other large animal models like the horse). At the same time, it allows for testing surgical procedures and medical devices in animals similar to human-size (e.g., bioengineered constructs, pacemakers, stents). On the other hand, sheep housing requires more space (barns for pens) which are not widely available. The commercial availability of molecular tools (e.g., antibodies) is also more limited than for rodents although these are increasing. Nonetheless, the practical disadvantages of the sheep as an experimental model do not make it inaccessible. Based on the aim of the study, the potential benefits may compensate its technical limitations. The publication and annotation of the sheep genome (Jiang et al., 2014) should improve the amount of commercially available reagents, thus facilitating the use of the ovine model in future studies. Concomitantly, the annotation of the sheep genome could support the development of useful biological tools for sheep as genetic models of human diseases (e.g., Huntington's Disease) (Pinnapureddy et al., 2015). Moreover, anesthesia and surgical equipment in sheep is more similar to humans than other large animals (like horses) and small rodents: Hence, using sheep does not require significant investment in large and specialized handling equipment, or surgical tables. At the same time, sheep can be sourced relatively easily and at low cost and they are considered as a socially acceptable animal model for research that raises fewer ethical issues than companion animals (Entrican et al., 2015; Rogers, 2016).

Sheep are used as models for a wide range of pathologies: cardiovascular diseases (Divincenti et al., 2014; Rabbani et al., 2017), orthopedics (Kon et al., 2000; Vandeweerd et al., 2013; Dias et al., 2018; Mcgovern et al., 2018; Music et al., 2018), respiratory function (Meeusen et al., 2009) and reproductive or pregnancy disorders (Andersen et al., 2018; Morrison et al., 2018). A major reason is that ruminants, as compared to rodents, share more anatomical and physiological characteristics (with exception of the digestive tract - testing efficacy of drugs may be complicated by the 4 -stomach system and uptake dynamics which defer from human gastrointestinal tract characteristics) with humans (Scheerlinck et al., 2008). This makes the sheep a useful model for preclinical and translational studies in fields of Tissue Engineering and Regenerative Medicine.

\section{Musculoskeletal Disorders}

Sheep have anatomical and biomechanical features relatively similar to humans (bone composition, weight, joint structure and architecture) which allows for good simulation of healing and remodeling processes of bone or cartilage tissue (Newman et al., 1995; Taylor et al., 2006). In addition, arthroscopic evaluation is possible in the sheep due to the size of their stifle joints. Therefore, the ovine species is the most commonly used large animal model in orthopedic research including studies on: cartilage repair (Music et al., 2018), meniscal repair (Hurtig et al., 1998; Tytherleigh-Strong et al., 2005), osteochondral tissue engineering (Sanjurjo-Rodriguez et al., 2017), tendon defects (Crovace et al., 2008; Martinello et al., 2013), osteoarthritis (Oakley et al., 2004; Gugjoo et al., 2019), and osteoporosis (Dias et al., 2018) among the others.

Sheep have been involved in studies for treating critical-sized bone defects using scaffolds with or without Mesenchymal Stem cells (MSCs). These treatments were shown to enhance bone formation and improve mechanical properties if compared to gold standard reparative methodologies like bone grafts (Kon et al., 2000; Cipitria et al., 2013; Fernandes et al., 2014; Berner et al., 2015; Mcgovern et al., 2018; Pobloth et al., 2018).

Although the ovine knee cartilage differs in thickness to human cartilage $(0.7-1.7 \mathrm{~mm}$ and $2.35 \mathrm{~mm}$, respectively), it provides a close match regarding mechanical properties for preclinical studies (Frisbie et al., 2006; Chu et al., 2010; Mclure et al., 2012). Tissue engineering approaches including different cell sources (as MSCs or chondrocytes) have been widely tested in the sheep for chondral/osteochondral defects (Lo Monaco et al., 2018; Gugjoo et al., 2019). Cells can also be applied with scaffolds of different nature to improve and support regeneration (Chitosan, type I/III collagen, b-TCP, collagen hydrogels) (Bernstein et al., 2013; Sanz-Ramos et al., 2014; Dias et al., 2018). For example, Hopper et al. (2015) used a biphasic collagen-GAG scaffold loaded with MSCs in a full-thickness osteochondral defect boosting cartilage repair while Zorzi et al. (2015) used a 1:1 chitosan-collagen scaffold seeded with human MSCs for articular cartilage regeneration (Hopper et al., 2015; Zorzi et al., 2015). Recently, a bilayered scaffold to simulate the bone-cartilage interface (chondral and bone tissue components) has been developed and tested in sheep (Schagemann et al., 2009; Fan et al., 2013).

Furthermore, regenerative strategies for osteoarthritis (usually induced by meniscectomy) have been investigated in sheep (Song et al., 2014; Desando et al., 2016; Feng et al., 2018). Of particular interest are the studies on scaffolds for meniscal repair because of its shared characteristics with the human meniscus (cellularity, vascularity, biomechanics) (Chevrier et al., 2009; Brzezinski et al., 2017). Gruchenberg et al. (2015) tested a silk fibroin scaffold as a meniscal implant after meniscectomy in sheep showing its biocompatibility (Gruchenberg et al., 2015). 
Spontaneous cartilage lesions (including osteoarthritis) have been observed in the sheep without experimental induction (Hurtig et al., 2011; Vandeweerd et al., 2013; Kuyinu et al., 2016). These are especially prevalent in aging sheep and might better recapitulate the human ailment than artificially created cartilage defects.

Sheep, like horses, are ideal candidates for tendinopathy modeling, but cheaper and easier to handle and house. Martinello et al. (2013) showed the treatment efficacy of MSCs, with or without PRP (platelet rich plasma), on collagenase-induced tendinitis in the superficial digital flexor tendon, with a better structural organization of the repaired tendon (Martinello et al., 2013). Deprés-Tremblay et al. (2018) tested the use of chitosan-PRP implants in an ovine acute defect model to mimic rotator cuff injuries. The implants led to an extensive bone remodeling and tissue ingrowth at the tendon-bone interface level (Deprés-Tremblay et al., 2018).

\section{Nervous System}

The ovine species also serves as an adequate and effective model to study peripheral nerve regeneration, because of the similar nerve size (Starritt et al., 2011) and similar regenerative behavior (Hems et al., 1994; Fullarton et al., 2001) compared to humans (Diogo et al., 2017).

Apart from conventional autografts and allografts for repairing peripheral nerve injuries in sheep (Frey et al., 1990; Matsuyama et al., 2000), tissue engineering techniques have also been applied. Casanas et al. (2014) applied a commercially available biodegradable scaffold with MSCs or PRP to reconstruct damaged radial and tibial nerves. The addition of MSCs, with or without PRP, led to the production of myelinated nerve fibers at the distal and proximal level with fiber regeneration and functional recovery after 6 months (Casanas et al., 2014). Radtke et al. (2011) compared the use of autologous nerve and acellularized vein grafts produced from spider silk. The outcomes obtained with the construct where similar to the nerve autograft results: axonal regeneration and myelination were achieved at 10 months (Radtke et al., 2011).

Using sheep models, MSCs were shown to play a reparative role in intervertebral disc regeneration. Injection of MSCs led to a reduction of degeneration of the discs compared to the control group (Freeman et al., 2016; Daly et al., 2018).

\section{Heart Disease}

Sheep have been frequently used as model for cardiovascular applications, especially for testing heart valves which have similar valve anatomy to the human and the sheep size permits access to the pulmonary and aortic valve. Kluin et al. (2017) developed an in-situ heart valve replacement for the pulmonary valve using a resorbable synthetic graft. 12 months post-implantation the tissue-engineered valve was shown to be colonized by host cells and replaced by newly formed tissue with a mature organization of the extracellular matrix without any sign of valve calcification (Kluin et al., 2017).

Cell therapies with MSCs have further been applied in acute myocardial infarction models to improve myocardial function. The inoculation of cells has been demonstrated to be safe, to increase vasculature, and to reduce fibrosis in the infarcted heart (Houtgraaf et al., 2013). Rabbani et al. (2017) showed that the injection of MSCs and endothelial cells (ECs) promoted angiogenesis and cardiac function, supposing that one of the mechanisms of action of the MSCs might lie in their differentiation potential toward the endothelial lineage (Rabbani et al., 2017).

Also, different tissue engineering approaches for the development of preclinical vascular grafts have been tested in the sheep model (Cummings et al., 2012; Aper et al., 2016; Fukunishi et al., 2016; Koobatian et al., 2016).

\section{Tissue Engineering Applications in Other Systems}

The ovine model has further been deployed to test regenerative approaches for treating respiratory disorders (similar airways structure and lung size to humans):

MSCs led to a reduction of inflammation and oedema and an improved oxygenation in sheep models of acute respiratory distress (Asmussen et al., 2014; Kocyildirim et al., 2017). In an induced emphysema model, the infusion of MSCs resulted in blood reperfusion of the damaged tissue and the formation of new extracellular matrix (Ingenito et al., 2012).

Recently, Kajbafzadeh et al. (2019) have tested the transplantation viability of decellularized kidneys in sheep.

The sheep model has also been described for wound healing studies because it allows for the creation of relatively large and deep wounds to mimic the typical scenario of traumatic injuries like burn injuries or decubitus ulcers. Martinello et al. (2018) used a sheep second intention wound healing model and showed how the intradermal and topical application of allogeneic MSCs led to a better re-epithelialization and dermal structure as compared to the control group at 42 days after wounding (Martinello et al., 2018). The identical model was recently used by Iacopetti et al. (2020) to compare secondary intention healing of wounds, treated with a topical application of commercially available hyaluronic acid, Manuka honey or Acemannan gel (Iacopetti et al., 2020).

In a similar ovine wound model, Liebsch et al. (2018) applied native spider silk as a wound dressing to test its biocompatibility and regenerative capacities (Liebsch et al., 2018). Mazzone et al. (2020) used bioengineered autologous skin substitutes to treat myelomeningocele in a spina bifida repair model. The skin substitute, made of hydrogel colonized by autologous fibroblasts and keratinocytes, was transplanted in utero. The skin substitutes showed a normal histology after 1 month (Mazzone et al., 2020).

Recently, Martines et al. (2020) evaluated the use of a lowtemperature atmospheric pressure plasma (ionized gas) as a treatment for extensive wounds in a sheep model. The plasma stimulated cell proliferation, angiogenesis and the development of skin adnexa; concomitantly, it reduced bacterial infection and inflammation (Martines et al., 2020).

A different tissue engineering approach to treat myelomeningocele was used by Watanabe et al. to treat spina bifida wounds with a gelatin/collagen sponge hybrid scaffold (Watanabe et al., 2016). 


\section{Embryonic/Fetal Healing}

True "scarless healing" is observed only in embryos and early fetus (Stramer et al., 2007). The restitutio ad integrum in embryos (Beredjiklian et al., 2003) is considered an ideal situation unmatched by any treatment regimen in adults. Therefore, an increasing amount of research studies is performed in embryos or fetal animals. To study the mechanism of fetal regeneration, relevant in vivo as well as in vitro models are required. Fetal sheep share many important physiological and developmental characteristics with humans and have hence proven themselves invaluable models for mammalian physiology (Almeida-Porada et al., 2004; Jeanblanc et al., 2014). Sheep frequently carry twins, which allows using one twin as uninjured control on a background of low genetic variation to enable differentiation between regular fetal development and fetal response injury.

Furthermore, their long gestational period ( 150 days) provides sufficient temporal resolution to translate findings obtained in sheep into human parameters (Almeida-Porada et al., 2004; Jeanblanc et al., 2014).

Fetal sheep have a fully functioning immune system by 75 days of gestation (gd) (Emmert et al., 2013). They produce leukocytes by 32 gd (Sawyer et al., 1978), TNF and Il-1 as early as 30-40 gd (Dziegielewska et al., 2000) and obtain the capability to form significant amounts of specific antibodies in response to antigenic stimulation as early as $70 \mathrm{gd}$ (Silverstein et al., 1963). Fetal lambs reject orthotopic skin grafts and stem cell xenotransplants placed post 75-77 gd (Silverstein et al., 1964) and mount an inflammatory response to injury by gestational day 65 (Nitsos et al., 2006; Moss et al., 2008; Herdrich et al., 2010; Morris et al., 2014).

For all these reasons, results obtained in the fetal lamb have been directly applicable to the understanding of human fetal growth and development and are highly predictive of clinical outcome in a variety of applications including in utero stem cell transplantation (Liechty et al., 2000; Almeida-Porada et al., 2004, 2007; Porada et al., 2005; Kuypers et al., 2012; Kim et al., 2013; Jeanblanc et al., 2014).

\section{Additional Considerations Regarding Sheep}

Due to their special stomach system (4 stomachs: rumen, reticulum, omasum, and abomasum) bio-availability and efficacy of drugs administered orally is questionable for the human GI tract. Moreover, prolonged inappetence and application of nonsteroidal anti-inflammatory drugs, antibiotics or both resulting in sustained high acidity in the abomasum may cause abomasal ulceration. Also stress, high dietary fiber and inadequate dietary fiber are believed to play a role (Ducharme, 2004; Fubini and Ducharme(eds), 2004).

Therefore, pain management and anti-microbial management have to be planned carefully and adapted to meet the special requirements of sheep (Lizarraga and Chambers, 2012; Varcoe et al., 2019). Sheep guidelines for pain assessment by facial expression are available (Hager et al., 2017) which may help managing pain.
Some of the most important advantages and disadvantages of using sheep as model animals are summarized in Table 3.

\section{PIGS AS ANIMAL MODELS}

\section{General Considerations}

Porcine models present the advantage of having similarities with the human in terms of gastrointestinal anatomy, metabolism and physiology (Court et al., 2004). When compared with other farm animals, pigs acquire early sexual maturity, sizeable litter size and have a quick reproduction time. They also breed yearround, which makes them highly suitable for biomedical research programs (Polejaeva et al., 2016). Due to these characteristics and the anatomical and physiological similarities, and also their size (young pigs have a size and body weight similar to human adults), pigs are widely used as models in organ transplantation and other surgical procedures (Kahn et al., 1988; Chari et al., 1994; Martin et al., 1999; He et al., 2013; Spetzler et al., 2015; Vogel et al., 2017), or as preclinical models in drug discovery (Swindle et al., 2012; Segatto et al., 2017), and numerous naturally occurring and generated genetic models of human disease (Swindle et al., 2012; Polejaeva et al., 2016). Hence, and similarly to the areas of medicine described above, the pig is gaining traction as the large animal model of choice for the study of tissue engineering and regenerative medicine products and applications, and of biomechanic studies. A good evidence of this is the steep rise in the number of publications in these broad areas in the past 30 years (Cone et al., 2017).

\section{Drug Discovery and Toxicology}

Traditionally, animal models used for preclinical testing of new drugs and toxicology studies have been rodents, mainly mice and rats, for the primary screening studies. Nonetheless, because translation from rodents into humans is often not fully

TABLE 3 | Advantages and disadvantages of the sheep as a model.

Advantages
Multiple large (critical size) defects
and serial sampling possible
Thickness of the knee cartilage is
similar to the human
Docile to handle
Availability, and acceptance by the
society as a research animal
Size is more similar to humans than
small animal models or horses
Publication and annotation of the
sheep genome
Imaging plus validated scoring
approaches available (esp. for
orthopedics)
Arthroscopy (also second look) plus
validated scoring approaches

validated scoring approaches

\section{Disadvantages}

Different breeds, not usually purpose-bred for research

Special facilities needed for housing, surgery, imaging, necropsy, technical skills Non-weight-bearing postoperatively is not feasible but can modulate with location

Different stomach system than humans

Ethical concerns but minor compared to companion animals Costs 
realized, regulatory agencies also demand the use of non-rodent models. Pigs are increasingly being used as an alternative to dogs or primates, the previous nonrodent species of choice (Swindle et al., 2012). However, due to growing pressure from the public, there has been a drive for new alternatives. The pig has been favored as a suitable alternative, since they have many anatomical and physiological features valuable for translational research and are already well accepted as one of the gold standard surgical models (Swindle et al., 2012). In particular, the cardiovascular system, skin and digestive tract closely mimic the human. Due to these similarities the metabolism and toxic effects of chemicals and drugs in pigs may more closely resemble the effects in man than some other laboratory animals. The minipig has been introduced recently as another alternative (Dalgaard, 2015) which is frequently used due to its smaller size and easier handling for drug discovery and toxicology applications (Mcanulty et al., 2011), boosted by the publication of the RETHINK project (Forster et al., 2010). Furthermore, the porcine CYP450 system has been studied and partially described, and their metabolic pathways have been found to be relatively analogous to humans, with substantial overlap in substrate specificity (Skaanild, 2006; Murayama et al., 2009).

\section{Generated Genetic Models}

With the advent of DNA recombination and gene editing technologies, modifying the pigs genome has enabled its use as a genetic model of numerous human diseases (Flisikowska et al., 2014; Yao et al., 2016). This is reflected in the multiple pig strains developed to study, amongst others, cancers, Duchenne muscular dystrophy, autosomal polycystic kidney disease, Huntington's disease, spinal muscular atrophy, cystic fibrosis, hemophilia A, X-linked severe combined immunodeficiency, retinitis pigmentosa, Stargardt's Disease, Alzheimer's disease, various forms of diabetes mellitus and cardiovascular diseases (Flisikowska et al., 2014; Rogers, 2016; Yao et al., 2016; Perleberg et al., 2018). From these, the RAG2 or RAG2/IL2RG KO pigs are particularly relevant for biomedical research, since they can accept xenografts and/or human bioengineered tissue/organs (Boettcher et al., 2018).

\section{Transplantation Models}

The pig has been used as a teaching and research animal model in surgery in the past decades. Starting in the 1990s, it became so prominent in academic and surgical training that it can be regarded as default model for non-survival surgical teaching classes, substituting the dog (Swindle, 2007). Its ubiquitous presence and use in academia, enabled also its widespread adoption in multiple models of liver, lung, heart, pancreas and kidney transplantation (Marubayashi et al., 1995; Martin et al., 1999; He et al., 2013; Fonouni et al., 2015; Mariscal et al., 2018). Furthermore, in transplantation medicine, the pig has also been proposed as xenograft donor, where porcine grafts have been transplanted into non-human primates with different degrees of success (Sachs et al., 2009; Griesemer et al., 2014). This has encouraged several research groups to target the porcine genome to eliminate the major xeno-antigen(s) recognized by human natural antibodies, in a so-called effort of humanizing the pig (Lai et al., 2002; Phelps et al., 2003; Petersen et al., 2011; Jeong et al., 2013). If ultimately realized, these procedures might enable the future xenotransplantation of porcine organs into humans as the main approach for transplantation medicine. Efforts are currently being taken to reduce the risk of viral zoonosis from porcine endogenous retrovirus (PERV), either by pharmacological treatment of PERV or by inactivating it with gene editing tools (Denner, 2017; Niu et al., 2017). Finally, other efforts have been concentrated on porcine uterus, urethra, kidney or liver bioengineering for transplantation (Baptista et al., 2011; Sullivan et al., 2012; Campo et al., 2017; Simoes et al., 2017). All these are an important testimony of the relevance of the pig as a vital translation research animal model.

\section{Skin}

The minipig has been used as a model in the development of dermatological products (Mitra et al., 2015; Yamamoto et al., 2017), and more recently, as a model for microbiome studies (Ericsson, 2019). As omnivores with an analogous gastrointestinal tract to humans, the well-characterized fecal microbiota of young and adult domestic pigs and other strains used in research also offers compositional resemblances to that of humans (Pedersen et al., 2013b; Zhao et al., 2015). Remarkably, many of these strains are used to investigate dietinduced obesity in genetically susceptible individuals and the same modifications (e.g., an increase in the ratio of Firmicutes to Bacteroidetes) observed between lean and obese humans are emulated in these pig models during the development of obesity (Pedersen et al., 2013a).

\section{Musculoskeletal Disorders}

In this particular area of biomedicine, the pig is experiencing a higher increase in adoption when compared to other large animal models (Cone et al., 2017) and several studies have been published assessing interspecies and interstrain differences in the anatomy and biomechanics of tissues and joints and their applicability in tissue engineering and regenerative medicine studies. Porcine models have a long history of use for studying the biomechanics of specific joints like the knee or the temporomandibular joint (TMJ), and specific tissues, including bone, cartilage, and ligaments (Xerogeanes et al., 1998; Sweigart et al., 2004; Proffen et al., 2012; Murphy et al., 2013; O’leary et al., 2017). Hence, the pig has been used with success to test the efficacy of bone substitute biomaterials (Li et al., 2015) and in osteochondral defect studies (Gotterbarm et al., 2008; Meng et al., 2020). Similarly, extensive research has been conducted with the pig in tendon and ligament repair as reviewed by others (Carpenter and Hankenson, 2004).

Pigs have also been used recently as a model of amyotrophic lateral sclerosis (ALS). This research has been based on the use of transgenic pigs with a mutated human copper/zinc superoxide dismutase 1 gene that mimics the human neurodegenerative disease in these pigs (Chieppa et al., 2014; Yang et al., 2014). Similarly, a pig model of Duchenne muscular dystrophy (DMD) has been created by Klymiuk et al. by deleting DMD exon 52 in male pig cells by gene targeting. The offspring generated by nuclear transfer exhibit absence of dystrophin 
in skeletal muscles, progressive dystrophic changes of skeletal muscles with impaired mobility, muscle weakness and a maximum life span of 3 months due to respiratory impairment (Klymiuk et al., 2013).

\section{Additional Considerations Regarding Pigs}

Pigs suffer from porcine malignant hyperthermia also known as porcine stress syndrome which is characterized by hyperthermia triggered by stress, certain anesthetic agents or intense exercise and may lead to sudden death (Nelson, 1990). Some of the most important advantages and disadvantages of using pigs as model animals are summarized in Table 4.

\section{COMPANION ANIMALS AS ANIMAL MODELS}

\section{General Considerations}

The importance of companion animals to serve as models for human disease has received significant attention through the One Health initiative which aims to "break through the species barrier" in a drive toward a better link between medical and veterinary research for the benefit of both the human and veterinary patient (Christopher, 2015).

While the definition of companion animals covers a range of animals this article extends only to the dog and cat as models, as they share remarkable similarities with the human and provide unique opportunities for developing advanced therapeutics.

One of the main reasons why dogs returned as a focus of genetic research is related to the specific population structure that has been created over the past 150-200 years.

To fully appreciate and exploit the biomedical potential of dogs (both as pets and as experimental animals), some insight into the unique canine population structure is necessary. Domesticated dogs were subjected to rigorous breeding selection, for instance for behavioral traits and/or specific morphological features such as excessive muscle formation, short limbs or a specific coat color (Larson et al., 2012). Illustrative for this process is the extreme size variation, by far the largest of all

TABLE 4 | Advantages and disadvantages of the pig as a model.

\begin{tabular}{ll}
\hline Advantages & Disadvantages \\
\hline $\begin{array}{l}\text { Size of the pigs: Multiple and } \\
\text { longitudinal measurements possible }\end{array}$ & $\begin{array}{l}\text { Ethical concerns but minor compared } \\
\text { to companion animals } \\
\text { Functional equivalence of various }\end{array}$ \\
$\begin{array}{l}\text { Special facilities needed for housing, } \\
\text { Genetic variation between breeds (cfr }\end{array}$ & surgery, imaging, necropsy \\
$\begin{array}{l}\text { human population), moderate genetic } \\
\text { variation within breeds (naturally }\end{array}$ & not feasible but can modulate with \\
occurring diseases) & location \\
Imaging plus validated scoring & Costs
\end{tabular}

approaches available (esp. for

orthopedics)

Arthroscopy (also second look) plus

validated scoring approaches mammals known, ranging from less than $1 \mathrm{~kg}$ for Chihuahua dogs to over $70 \mathrm{~kg}$ for Irish wolfhounds and Neapolitan Mastiffs. This selection process was intensified in the last two centuries and resulted in isolated genetic populations of dog breeds (Parker et al., 2010). Whereas the genetic variation over the various breeds remained intact, the reduced genetic variability within breeds worked as a genetic amplifier and offers "genetic dissection microscope" for research (LindbladToh et al., 2005; Parker et al., 2010; Larson et al., 2012; Van Steenbeek et al., 2016). Together with the selection for unique traits, an increased risk for the development of specific inheritable disorders arose within breeds, providing physiologically relevant models corresponding to human conditions. To make the best out of the current situation may be to exploit the downside of inbreeding as a gene-discovery instrument for causative and modifier genes involved in complex diseases and/or rare diseases.

\section{Canine Inherited Copper Toxicosis}

The trace element copper is indispensable for critical biochemical processes such as enzyme function, for instance cytochrome $c$ oxidase (part of the respiratory enzyme complex) or superoxide dismutase (conversion of superoxide radicals into molecular oxygen or hydrogen peroxide) (Inesi, 2017). Since copper is a transition element (reduced as $\mathrm{Cu}+$ and oxidized as $\left.\mathrm{Cu}^{2}+\right)$ its Jekyll and Hyde character becomes evident in the involvement in chemical reactions leading to the production of reactive oxygen species. In a Fenton reaction, $\mathrm{Cu}^{+}$catalyzes the formation of the highly reactive hydroxyl radical $(\mathrm{OH} \cdot)$. In the converse Haber-Weiss reaction $\mathrm{Cu}^{2+}$ inactivates the damaging superoxide radical $\mathrm{O}_{2}$. Therefore, regulation of its intracellular free concentrations is of utmost importance and needs to be controlled within very narrow limits (Kim et al., 2008). Several inherited copper-related diseases are diagnosed in men such as Menke's Disease (copper deficiency disorder), Wilson Disease (WD, copper accumulation), and the very rare Indian childhood cirrhosis (Tanner, 1998), endemic Tyrolean infantile cirrhosis (Muller et al., 1996), and idiopathic copper toxicosis (Scheinberg and Sternlieb, 1996). These all are rare diseases posing specific obstacles for researchers aiming to dissect molecular pathways and for rational drug design. These obstacles include limited financial resources compared to diseases affecting large numbers of patients, smaller patient cohorts for clinical phase 1-3 studies, difficulties for properly matched case-control studies in genetics and molecular signaling studies.

Copper disorders also affect sheep and dogs (Twedt et al., 1979; Haywood et al., 2001; Fuentealba and Aburto, 2003). Deleteriously increased levels of hepatic copper are described in a number of dog breeds including Bedlington terriers, Skye terriers, West-Highland White terriers, Doberman, Dalmatians and Labrador retrievers (Twedt et al., 1979; Haywood et al., 1988; Thornburg et al., 1996; Thornburg, 1998; Webb et al., 2002; Hoffmann et al., 2006). In 1999 genetic mapping studies revealed that the copper toxicosis locus within Bedlington terriers was located on canine chromosome 10. 3 years after positional cloning a $13 \mathrm{kB}$ deletion covering exon- 2 of 
the murrl gene was identified as the causative mutation for Bedlington terrier copper toxicosis (Van De Sluis et al., 1999, 2002). The causative role of murr1 mutations in WD is a matter of debate. Stuehler et al. found an association between murr1 mutations and WD, whereas two other papers did not detect a correlation between murr1 mutations and WD (Stuehler et al., 2004; Lovicu et al., 2006; Wu et al., 2006). This novel gene product, currently called COMMD1 (COpper Metabolism Murr1 Domain-containing protein 1) had no known function at the time it was discovered, and the mechanism of action related to hepatic copper accumulation remained enigmatic. The discovery that COMMD1 and ATP7B interact intracellularly revealed a mechanistic link between COMMD1 protein and copper toxicosis, later confirmed for the Menkes Disease protein ATP7A (De Bie et al., 2007; Vonk et al., 2012).

The discovery of the COMMD1 mutation and subsequent investigations into functions of COMMD1 is an intriguing example for a useful exploitation of inbred dog strains to reveal novel molecular and genetic pathways. Genetically speaking the big advantage of canine genetics to benefit human genetics is the ease to discover modifier genes. This is a needle-in-a-haystack technology in men even today, but the specific genetic population structure in inbred dogs clearly facilitates this approach.

Labrador retrievers are among the most popular breeds in the Western world.

It was already known for a long time that approximately one in every three first-line relatives of Labradors retrievers with copper toxicosis had elevated copper levels (Hoffmann et al., 2006). This pushed investigations into whether or not Labrador retrievers were new model animals for WD and as a consequence propelled genetic studies (Fieten et al., 2014). A SNP based genome-wide association study aiming to discover the genetic background of inherited copper toxicosis in Labrador retrievers included over 200 Labrador retrievers (154F, $81 \mathrm{M}$ cases; 37F and $22 \mathrm{M}$ as replication cohort) in the Netherlands that were genotyped on the 170k SNP Illumina Canine HD Bead Chip (Fieten et al., 2016). For details on the mechanism of action of these mutations the readers are referred elsewhere (Fieten et al., 2016). Approximately $12 \%$ of the phenotype can be explained by two mutations identified in Labrador retrievers. Since mutations in these genes were already described in copper-related disorders, it remains to be seen what other as-yet-unidentified genetic mutations will be discovered.

This genetic study clearly illustrates the power of the canine model. Explaining $12 \%$ of the phenotypic variation with an ample 250 dogs doesn't even remotely resemble the number of human patients used to explain similar percentage for age at menarche, Inflammatory Bowel Disease (IBD) and Rheumatoid arthritis (RA) for which over 100,000 individuals were included (Elks et al., 2010; Okada et al., 2014; Liu et al., 2015).

The examples prove that due to the specific population structure of inbred dog breeds, genetic studies can be successfully performed even for rare and/or complex genetic diseases.

In order to investigate COMMD1-deficient dogs as a preclinical model for liver stem cell transplantations, a breeding colony of five COMMD1 deficient dogs was created on a Beagle background and followed for over 4 years (Favier et al., 2011, 2012; Favier et al., 2015). This model for inherited copper toxicosis has some practical features specifically relevant for preclinical studies that aim to investigate surgical procedures. In contrast to mouse models, that are sacrificed for every liver measurement, the dogs' size allowed for a true longitudinal study permitting liver biopsy sampling twice a year.

\section{Heart Disease}

The most prevalent non ischaemic cardiomyopathies in humans are hypertrophic cardiomyopathy (HCM) and dilated cardiomyopathy (DCM), reported to affect 1 in 500 and 35 in 100,000 people, respectively (2017, Heron, 2016). Arrhythmogenic ventricular cardiomyoapthy (AVC) is also recognized as an important and distinct form of cardiomyopathy. Together they are associated with mechanical and/or electrical dysfunction and manifestations of the disease can range from microscopic alterations in cardiomyocytes and cardic fibroblasts to heart failure (which results in inadequate tissue perfusion and fluid retention) and arrhythmia which may cause sudden death. In veterinary species HCM is the most common feline cardiac disease affecting around 1 in 15 cats and DCM is the second most common cardiac disease in dogs and can affect a wide variety of breeds including the Doberman where its cumulative prevalance is as high as $44 \%$. AVC has been comprehensively described in the Boxer breed at the molecular, cellular and clinical levels. All three cardiomyopathies share striking pathological and clinical similarities with the human disease. While there has been progress in the management of the symptoms associated with these cardiomyopathies in human patients, the actual disease processes remain a challenge to treat as there are few therapies that target the underlying pathology. There has therefore been an emphasis on the use of regenerative cellular therapies, although most studies have focused on ischaemic myocardial disease using mesenchymal stem cells (MSCs) derived mostly from bone marrow or adipose tissue. Stem cells derived from myocardial tissue have more recently been developed and have been tested in a number of induced disease models. A comparison of MSCs and cardiosphere derived cells (CDCs) suggests that CDCs are more efficacious in their ability to regenerate the myocardium ( $\mathrm{Li}$ et al., 2012) and phase 1 clinical trials using autologous CDCs show encouraging results (Bolli et al., 2011; Makkar et al., 2012; Malliaras et al., 2014).

The development of cell-based approaches in the feline and canine clinic will have significant benefits for translation in human cardiomyopathy treatment.

\section{Human and Feline Hypertrophic Cardiomyopathy}

Hypertrophic cardiomyopathy is the most common cardiomyopathy in both humans and cats with a prevalence of approximately $0.1-0.2 \%$ and $16 \%$, respectively (Maron et al., 1995; Payne et al., 2010; Semsarian et al., 2015; Husser et al., 2018). There is increasing literature that supports the cat as an animal model of human HCM and evidence suggests it is 
essentially the same disease in both species (Maron and Fox, 2015). HCM is characterized by left ventricular hypertrophy in the absence of systemic causes and can result in heart failure and/or sudden death. In humans genetic mutations are identified in $60 \%$ of HCM cases, mainly in genes encoding sarcomeric proteins (Cahill et al., 2013). HCM in the cat is also considered to have a familial cause although only two causative mutations have so far been identified (Maron and Fox, 2015), in contrast several hundred have been identified in human patients. Both of the feline mutations occur in the cardiac myosin binding protein $\mathrm{C}$ (MYBPC3) gene, one of which occurs in the Maine Coon breed (A31P mutation) and the other in the Ragdoll breed (R820W mutation) (Meurs et al., 2005, 2007). It is of interest to note that one specific non-truncating mutation, MYBPC $3 / \mathrm{R} 820 \mathrm{~W}$, that occurs in Ragdolls has been identified in a human family with HCM (Ripoll Vera et al., 2010; Borgeat et al., 2014). The role sarcomeric mutations play in the development of HCM in non-pedigree cats requires further investigation.

The underlying molecular pathogenesis driving HCM remains to be elucidated although a common pathway is thought to exist in both humans and cats in which altered calcium handling within the myofilaments enhances calcium sensitivity, causing maximal force production and energy deficiency promoting mitochondrial dysfunction, cell death, fibrosis and cardiomyocyte hypertrophy (Huke and Knollmann, 2010; Marston, 2011; Song et al., 2013; Robinson et al., 2018).

Studies using myocardial tissue from a cat homozygous for the MYBPC3/R820W mutation suggest that increased myofilament calcium sensitivity can occur in the absence of haploinsufficiency, which is common feature in human MYBPC3 mutations (Messer et al., 2017). Increased myofilament calcium sensitivity was also seen in other HCM affected cats of unknown genotype but not in unaffected cats. An additional feature of the study was that the calcium sensitivity of the sarcomere is uncoupled from the phosphorylation status of troponin I, although it remains unclear how mutations outside the troponin complex cause this uncoupling phenomenon. The reasons clearly are complex but the similarities at the molecular level show the cat to be a highly relevant natural disease model for human HCM for deciphering the mechanisms. Targeting the disease with Epigallocatechin-3-gallate, for example can reverse troponin I phosphorylation uncoupling in cat HCM (Messer et al., 2017) which has been replicated in human HCM samples (Sheehan et al., 2018).

Such studies highlight the need to identify detailed molecular mechanisms for precise drug targeting. However, there are practical limitations with obtaining sufficient heart tissue and the survival of isolated primary cardiomyocytes is poor. Induced pluripotent stem cells (iPSC) or embryonic stem cells (ESCs) represent an alternative and robust source for preparing cardiomyocytes. The development and use of human ESCs represents an ethical dilemma and while less of an issue in veterinary species, there are only two reports of ES-like cells from cats, but these do not replicate indefinitely in culture unlike true ES cells. iPSCs on the other hand do not have the concerns associated with ESCs and can be relatively readily prepared from somatic cells.
Feline iPSCs have recently been reported for the first time by our group, the development of which represents a significant step in the generation of iPSC derived cardiomyocytes from a veterinary species (Dutton et al., 2019). It paves the way for generating further cell lines from feline patients carrying the HCM causing MYBPC3/R820W mutation to test novel therapeutics for modifying the disease. iPSCs can further be manipulated with technologies such as Clustered Regularly Interspaced Short Palindromic Repeats (CRISPR) to enable targeted genetic manipulation of both normal and diseased patient cell lines (Cai et al., 2018; Sasaki-Honda et al., 2018).

iPSCs derived from patients with HCM or iPSCs with a genetic mutation inserted using CRISPR to model HCM, display characteristics of hypertrophic cardiomyocytes in culture (Mosqueira et al., 2018) suggesting the suitability of the approach in establishing cell models of HCM. The availability of feline iPSC lines will enable dissecting out the molecular mechanisms of HCM enabling targeted drug screening where promising molecules can be rapidly assessed in the feline clinic with the potential of swift translation to human patients.

\section{Human and Canine Dilated and Arrhythmogenic Ventricular Cardiomyopathy}

DCM is the third most common inherited myocardial disease in humans with an estimated prevalance of $0.35 \%$ and some 2.5 million cases globally affected ${ }^{6}$. It is the second most common cardiac disease in dogs and accounts for $10 \%$ of canine cardiac diagnosis (Egenvall et al., 2006). As with feline HCM there are remarkable similarities in the pathophysiology of DCM between human and dog. Although it is a heterogenous disease it is characterized by progressive enlargement of the left ventricle that leads to reduced systolic function, congestive heart failure and a variety of arrhythmias. Underlying causes include systemic disorders such as hypertension and atherosclerosis in humans but is also now recognized as a primary genetic disorder that may manifest with or without accompanying predisposing factors. Giant dog breeds such as the Great Dane and Newfoundlands are at risk and a genetic basis has been proposed in some dog breeds including the Doberman Pinscher and Boxer in which the disease is both common and severe with a cumulative prevalence in European Dobermans $>8$ years of age of $44 \%$ (Mausberg et al., 2011; Simpson et al., 2015a,b). A genetic deletion in the Pyruvate Dehydrogenase Kinase 4 (PDK4) gene has been reported. PDK4 is critical in regulating mitochondrial energy metabolism as the genetic deletion predisposes affected individuals to developing DCM as it results in chronic energy attenuation (Meurs et al., 2012). More recently a missense variant in the titin gene has been reported in affected Doberman pinscher dogs negative for the PDK4 mutation. The Boxer breed has a distinct form of cardiomyopathy that closely

\footnotetext{
${ }^{6}$ https://www.bhf.org.uk/what-we-do/our-research/heart-statistics/heartstatistics-publications/cardiovascular-disease-statistics-2017
} 
resembles AVC in humans (Vischer et al., 2017). A causative mutation in the striatin gene has been identified in Boxer dogs in the United States but this was not seen in the UK population (Meurs et al., 2010; Cattanach et al., 2015). The role of genetics in other dog breeds with DCM remain to be better described.

Histopathological observations of the myocardium show that canine cardiomyopathy displays either an attenuated wavy fiber type and fibro-fatty infiltration type (Tidholm and Jonsson, 2005) with the latter highly similar to AVC in humans. These findings emphasize the comparable pathological changes and clinical presentation between the two species (Basso et al., 2004; Meurs et al., 2014; Vila et al., 2017). The pathophysiologic mechanism underlying AVC is thought to involve mechanical and electrical decoupling and cardiomyocyte apoptosis (Wess et al., 2010) which with the fibro-fatty replacement of the myocardium are considered primary drivers for risk of arrhythmia and sudden cardiac death. Dogs that survive develop progressive ventricular dilation and systolic dysfunction leading to congestive heart failure (Wess et al., 2010; Meurs et al., 2014).

There have been efforts to use stem cells for the treatment of cardiac disease in humans spurred by observations that the adult heart processes regenerative ability (Condorelli et al., 2001; Nadal-Ginard et al., 2003). A number of clinical trials are under way or completed using adipose or bone marrow derived mesenchymal stem cells (MSC) although these are predominantly for ischaemic disease. One published study in Doberman pinchers with DCM administered allogeneic adipose derived MSCs that were virally transfected to overexpress stromal derived factor-1 to enhance homing and engrafting capabilities of endogenous MSCs to the myocardium (Pogue et al., 2013). Although no significant improvements in survival rates were found at 2year follow up, the study demonstrated that the dog model of naturally occurring DCM can be utilized to overcome a number of challenges for regenerative therapies. There is increasing interest in CDCs as they appear to possess a superior ability to regenerate the myocardium ( $\mathrm{Li}$ et al., 2012) compared to MSCs. CDCs are a heterogenous cardiac stem cell population which display features typical of stem cells such as forming clones, self-renewal and commitment to multiple lineages (Johnston et al., 2009; Chimenti et al., 2010; Cheng et al., 2014; Hensley et al., 2015). The use of CDCs clearly is not practical because of the need to sample from the patient and also because of expansion of cells from a diseased individual which adds to patient risk, time and treatment costs. Allogeneic cells offer an alternative off-the-shelf-product but risks include immunological complications that may lead to graft versus host disease. Work in a rodent model and other induced disease models suggests allogeneic CDCs are non-immunogenic (Malliaras et al., 2012). Allogeneic CDCs have been tested in a small clinical trial in dogs affected with DCM (Hensley et al., 2017) and no significant adverse effects were reported. Nevertheless, the process of cryofreezing of cell stocks may potentially alter intrinsic properties of the cells as has been shown for MSCs (Moezzi et al., 2005). Effects such as chromosome abnormalities resulting in abberrant cellular activity and risk of tumorigenesis may compromise their clinical use. However we have demonstrated that cryopreservation of dog CDCs does not alter their immunophenotype and cellular characteristics (Dutton et al., 2018a). Furthermore, we have shown at a molecular level that canine CDCs are also immune- privileged similar to the immunomodulatory function of MSCs (Dutton et al., 2018b) and cryopreservation retains this property suggesting they are safe to use in vivo.

\section{Musculoskeletal Disorders in Companion Animals Osteoarthritis}

Dog models have long been used to study joint disorders particularly osteoarthritis. The canine model for osteoarthritis has been more commonly used than the horse, sheep or goat model (Mccoy, 2015). One of the reasons might be the easier post-operative management and follow up using various exercise regimes on e.g., treadmills (Mccoy, 2015). While there are some similarities in cartilage anatomy between humans and dogs, the standing angle in the hindlimb in dogs is much larger. This should be considered when biomechanical aspects are compared and evaluated (Mccoy, 2015). As stated previously the cartilage thickness in dogs is $0.6-1.3 \mathrm{~mm}$ and cartilage defects are considered to have a critical size at a minimum diameter of $4 \mathrm{~mm}$. Experimental OA is preferably induced in the stifle joint (Pond and Nuki, 1973; Marijnissen et al., 2002; Kuroki et al., 2011), whereas naturally occurring disease is also common in the elbow or hip joint with an estimation prevalence of OA affecting $20 \%$ of adult dogs (Mccoy, 2015).

With respect to osteoarthritis dogs are divided in two classes, non-chondordystrophic (NCD) and chondrodystrophic (CD) dogs. The last group presents with disproportionally short limbs, caused by aberrant endochondral ossification of long bones. Dachshunds are typical examples. The molecular mechanisms of this short limb phenotype is associated with a retrogene insertion of the FGF4 fibroblast growth factor 4 gene. This leads to elevated levels of FGF3 signaling. Interestingly, whereas $\mathrm{CD}$ dogs are more prone to intravertebral disc degeneration (IVDD), the insertion of the retrogene renders short-limb dogs less likely to develop OA in comparison with NC-dog (Tellegen et al., 2019). These examples emphasize the need to carefully select for a specific dog breed for musculoskeletal investigations.

\section{Intervertebral Disc Degeneration}

Despite walking on four legs in contrast to men walking on two only, both species develop intervertebral disc degeneration with great similarities and similar prevalence. Link-N is a protein involved in proteoglycan stabilization (beneficial) and is highly homologous between men and dogs. However, neither human link-N nor canine link-N can protect cultured canine intervertebral disc cells form degeneration, whereas human link-N improved glycosaminoglycn deposition 
in human and bovine chondrocyte-like cell cultures (Bach et al., 2017).

In a classcial pre-clinical study a controlled release system for the COX-2 inhibitor celecoxib (cyclooxygenase-2) was tested in a dog model for IVDD (Tellegen et al., 2018). Since celecoxib prevented IVDD progression and reduced inflammation, follow-up studes will be conducted in a clincal study aiming to eliviate the chronic pain associated with low back pain.

\section{Cranial Cruciate Disease and Meniscal Injury}

Naturally occurring cranial cruciate disease has been studied extensively in veterinary medicine (Cook, 2010; Bergh et al., 2014). It can therefore be stated, that the pathophysiology differs between injuries in humans and canines, because dogs typically suffer from degenerative ruptures (Comerford et al., 2011) as compared to acute traumatic injuries seen in humans. To study new treatment approaches and validate their success, experimental models with artificially severed cruciate ligaments should be employed (Bozynski et al., 2016).

Dogs also suffer from naturally occurring meniscal pathologies and hence lend themselves as potential translational models to study mechanisms of degeneration or for testing new treatment strategies (Krupkova et al., 2018). The canine meniscus has comparable anatomic features (vascularization, cellularity, collagen structure) and similar permeability to the human (Sweigart et al., 2004; Deponti et al., 2015). However, some differences between canine and human menisci especially with regard to biomechanical properties such as the aggregate- and shear-modulus should be pointed out (Sweigart et al., 2004; Gupte et al., 2007).

\section{Nervous System}

Cats often serve as models to study spinal cord healing and comparative aspects in neurosurgery (Barbeau and Rossignol, 1987; Bélanger et al., 1996; Abelew et al., 2000; Bouyer and Rossignol, 2003). Biomechanical motion analyses using treadmills and force plates as well as electromyography (EMG) are performed to evaluate spine kinematics and muscular properties following experimentally induced spinal cord or cerebral lesions.

\section{Additional Considerations Regarding Companion Animals}

Dogs and cats are companion animals and pets and as such subject of unprecedented love and care in our society. Therefore, studies involving dogs and/or cats raise more ethical debate than other animal studies. However, most studies in these animals use clinical cases seen in veterinary hospitals and clinics, which highlights the importance of this underused resource for research. Some of the most important advantages and disadvantages of using dogs as model animals are summarized in Table 5.

TABLE 5 | (a) Advantages and disadvantages of canine research in general and hepatology in particular. (b) Advantages and disadvantages of companion animals as models.

\section{Advantages}

Size of the dogs: Multiple and longitudinal measurements possible

Functional equivalence of various diseases in men and dogs/cats

Large genetic variation between breeds (cfr human population), limited genetic variation within breeds (genetic magnifier glass)

Imaging plus validated scoring approaches available (esp. for orthopedics)

Dogs: Arthroscopy (also second look) plus validated scoring approaches

Dogs: Objective weight-bearing of legs possible (force plate analysis)

Dogs: Size variations cover new-born human-size until adult size

Clinical need, large patient population (pets) available

\section{Disadvantages}

Ethical concerns - companion animals More of a concern if experimental use

No canine hepatitis virus causally correlated with canine hepatitis

Specific drug intolerances for specific breeds 
veterinary medicine can mutually benefit if one appreciates the similarities.

\section{AUTHOR CONTRIBUTIONS}

IR contributed to conceptualization, writing the manuscript, merging the parts contributed by other authors, and revision and editing of the manuscript. PB, AL-C, LM, MP, ES-F, LD, DC, and FS wrote the manuscript. FJ revised and edited the manuscript. JD wrote, revised, and edited the manuscript. LP conceived the

\section{REFERENCES}

Abelew, T. A., Miller, M. D., Cope, T. C., and Nichols, T. R. (2000). Local loss of proprioception results in disruption of interjoint coordination during locomotion in the cat. J. Neurophysiol. 84, 2709-2714. doi: 10.1152/jn.2000.84. 5.2709

Aigner, T., Cook, J. L., Gerwin, N., Glasson, S. S., Laverty, S., Little, C. B., et al. (2010). Histopathology atlas of animal model systems - overview of guiding principles. Osteoarthritis Cartilage 18(Suppl. 3), S2-S6.

Al Abri, R., Kolethekkat, A. A., Kelleher, M. O., Myles, L. M., and Glasby, M. A. (2014). Effect of locally administered ciliary neurotrophic factor on the survival of transected and repaired adult sheep facial nerve. Oman Med. J. 29, 208-213. doi: 10.5001/omj.2014.51

Almeida-Porada, G., Porada, C., Gupta, N., Torabi, A., Thain, D., and Zanjani, E. D. (2007). The human-sheep chimeras as a model for human stem cell mobilization and evaluation of hematopoietic grafts' potential. Exp. Hematol. 35, 1594-1600. doi: 10.1016/j.exphem.2007.07.009

Almeida-Porada, G., Porada, C., and Zanjani, E. D. (2004). Plasticity of human stem cells in the fetal sheep model of human stem cell transplantation. Int. J. Hematol. 79, 1-6. doi: 10.1007/bf02983526

Andarawis-Puri, N., Flatow, E. L., and Soslowsky, L. J. (2015). Tendon basic science: development, repair, regeneration, and healing. J. Orthop. Res. 33, 780-784. doi: 10.1002/jor.22869

Andersen, M. D., Alstrup, A. K. O., Duvald, C. S., Mikkelsen, E. F. R., Vendelbo, M. H., and Ovesen, P. G. (2018). "Animal models of fetal medicine and obstetrics," in Experimental Animal Models of Human Diseases - An Effective Therapeutic Strategy ed. B. Ibeh (London: InTech).

Ansorge, H. L., Hsu, J. E., Edelstein, L., Adams, S., Birk, D. E., and Soslowsky, L. J. (2012). Recapitulation of the Achilles tendon mechanical properties during neonatal development: a study of differential healing during two stages of development in a mouse model. J. Orthop. Res. 30, 448-456. doi: 10.1002/jor. 21542

Aper, T., Wilhelmi, M., Gebhardt, C., Hoeffler, K., Benecke, N., Hilfiker, A., et al. (2016). Novel method for the generation of tissue-engineered vascular grafts based on a highly compacted fibrin matrix. Acta Biomater. 29, 21-32. doi: 10.1016/j.actbio.2015.10.012

Asmussen, S., Ito, H., Traber, D. L., Lee, J. W., Cox, R. A., Hawkins, H. K., et al. (2014). Human mesenchymal stem cells reduce the severity of acute lung injury in a sheep model of bacterial pneumonia. Thorax 69, 819-825. doi: 10.1136/ thoraxjnl-2013-204980

Aun, M. V., Bonamichi-Santos, R., Arantes-Costa, F. M., Kalil, J., and GiavinaBianchi, P. (2017). Animal models of asthma: utility and limitations. J. Asthma Allergy 10, 293-301. doi: 10.2147/jaa.s121092

Bach, F. C., Laagland, L. T., Grant, M. P., Creemers, L. B., Ito, K., Meij, B. P., et al. (2017). Link-N: the missing link towards intervertebral disc repair is species-specific. PLoS One 12:e0187831. doi: 10.1371/journal.pone.0187831

Baptista, P. M., Siddiqui, M. M., Lozier, G., Rodriguez, S. R., Atala, A., and Soker, S. (2011). The use of whole organ decellularization for the generation of a vascularized liver organoid. Hepatology 53, 604-617. doi: 10.1002/hep.24067

Barbeau, H., and Rossignol, S. (1987). Recovery of locomotion after chronic spinalization in the adult cat. Brain Res. 412, 84-95. doi: 10.1016/0006-8993(87) 91442-9 idea and wrote, revised, and edited the manuscript. All authors contributed to the article and approved the submitted version.

\section{ACKNOWLEDGMENTS}

We would like to thank Niklas Dresen, Institute of Veterinary Anatomy, University Leipzig as well as John Breteler, Elfriede Cremer, Bernhard Cremer, and Elisabeth Schieder for the provided graphical support and Michaela Hauser for formatting the references. PB acknowledges the funded projects PI15/00563 and PI18/00529 from ISCIII, Spain.

Baron, R., Tross, R., and Vignery, A. (1984). Evidence of sequential remodeling in rat trabecular bone: morphology, dynamic histomorphometry, and changes during skeletal maturation. Anat. Rec. 208, 137-145. doi: 10.1002/ar. 1092080114

Basso, C., Fox, P. R., Meurs, K. M., Towbin, J. A., Spier, A. W., Calabrese, F., et al. (2004). Arrhythmogenic right ventricular cardiomyopathy causing sudden cardiac death in boxer dogs: a new animal model of human disease. Circulation 109, 1180-1185. doi: 10.1161/01.cir.0000118494.07530.65

Baumgartner, W., Gauly, M., Schuh, M., Hildebrandt, N., Moritz, A., Christen, C., et al. (2009). Klinische Propädeutik der Haus-und Heimtiere. Stuttgart: Enke Verlag.

Baxter, G. M., and Morrison, S. (2008). Complications of unilateral weight bearing. Vet. Clin. North Am. Equine Pract. 24, 621-642. ix, doi: 10.1016/j.cveq.2008. 10.006

Becerra, P., Valdes Vazquez, M. A., Dudhia, J., Fiske-Jackson, A. R., Neves, F., Hartman, N. G., et al. (2013). Distribution of injected technetium(99m)-labeled mesenchymal stem cells in horses with naturally occurring tendinopathy. J. Orthop. Res. 31, 1096-1102. doi: 10.1002/jor.22338

Bélanger, M., Drew, T., Provencher, J., and Rossignol, S. (1996). A comparison of treadmill locomotion in adult cats before and after spinal transection. J. Neurophysiol. 76, 471-491. doi: 10.1152/jn.1996.76.1.471

Bendele, A. M. (2001). Animal models of osteoarthritis. J. Musculoskelet. Neuronal Interact. 1, 363-376.

Bentley, G. (1975). Articular cartilage studies and osteoarthrosis. Ann. R. Coll. Surg. Engl. 57, 86-100.

Beredjiklian, P. K., Favata, M., Cartmell, J. S., Flanagan, C. L., Crombleholme, T. M., and Soslowsky, L. J. (2003). Regenerative versus reparative healing in tendon: a study of biomechanical and histological properties in fetal sheep. Ann. Biomed. Eng. 31, 1143-1152. doi: 10.1114/1.1616931

Bergh, M. S., Sullivan, C., Ferrell, C. L., Troy, J., and Budsberg, S. C. (2014). Systematic review of surgical treatments for cranial cruciate ligament disease in dogs. J. Am. Anim. Hosp. Assoc. 50, 315-321. doi: 10.5326/jaaha-ms6356

Berner, A., Henkel, J., Woodruff, M. A., Steck, R., Nerlich, M., Schuetz, M. A., et al. (2015). Delayed minimally invasive injection of allogenic bone marrow stromal cell sheets regenerates large bone defects in an ovine preclinical animal model. Stem Cells Transl. Med. 4, 503-512. doi: 10.5966/sctm.2014-0244

Berner, D., Brehm, W., Gerlach, K., Gittel, C., Offhaus, J., Paebst, F., et al. (2016). Longitudinal cell tracking and simultaneous monitoring of tissue regeneration after cell treatment of natural tendon disease by low-field magnetic resonance imaging. Stem Cells Int. 2016:1207190.

Bernstein, A., Niemeyer, P., Salzmann, G., Sudkamp, N. P., Hube, R., Klehm, J., et al. (2013). Microporous calcium phosphate ceramics as tissue engineering scaffolds for the repair of osteochondral defects: Histological results. Acta Biomater. 9, 7490-7505. doi: 10.1016/j.actbio.2013.03.021

Blume, C., and Davies, D. E. (2013). In vitro and ex vivo models of human asthma. Eur. J. Pharm. Biopharm. 84, 394-400.

Boettcher, A. N., Loving, C. L., Cunnick, J. E., and Tuggle, C. K. (2018). Development of Severe Combined Immunodeficient (Scid) pig models for translational cancer modeling: future insights on how humanized Scid Pigs can improve preclinical cancer research. Front. Oncol. 8:559. doi: 10.3389/fonc. 2018.00559 
Bolli, R., Chugh, A. R., D’amario, D., Loughran, J. H., Stoddard, M. F., Ikram, S., et al. (2011). Cardiac stem cells in patients with ischaemic cardiomyopathy (Scipio): initial results of a randomised phase 1 trial. Lancet 378, 1847-1857. doi: 10.1016/s0140-6736(11)61590-0

Bonamichi-Santos, R., Aun, M. V., Agondi, R. C., Kalil, J., and Giavina-Bianchi, P. (2015). Microbiome and Asthma: What have experimental models already taught us? J. Immunol. Res. 2015:614758.

Borgeat, K., Casamian-Sorrosal, D., Helps, C., Luis Fuentes, V., and Connolly, D. J. (2014). Association of the myosin binding protein C3 mutation (MYBPC3 R820W) with cardiac death in a survey of 236 Ragdoll cats. J. Vet. Cardiol. 16, 73-80. doi: 10.1016/j.jvc.2014.03.005

Bos, P. K., Kops, N., Verhaar, J. A., and Van Osch, G. J. (2008). Cellular origin of neocartilage formed at wound edges of articular cartilage in a tissue culture experiment. Osteoarthritis Cartilage 16, 204-211. doi: 10.1016/j.joca.2007. 06.007

Bouyer, L. J., and Rossignol, S. (2003). Contribution of cutaneous inputs from the hindpaw to the control of locomotion. II. Spinal cats. J. Neurophysiol. 90, 3640-3653. doi: 10.1152/jn.00497.2003

Bozynski, C. C., Stannard, J. P., Smith, P., Hanypsiak, B. T., Kuroki, K., Stoker, A., et al. (2016). Acute management of anterior cruciate ligament injuries using novel canine models. J. Knee Surg. 29, 594-603. doi: 10.1055/s-0035-1570115

Brittberg, M., and Winalski, C. S. (2003). Evaluation of cartilage injuries and repair. J. Bone Joint. Surg. Am. 85-A, 58-69. doi: 10.2106/00004623-200300002-00008

Broeckx, S. Y., Martens, A. M., Bertone, A. L., Van Brantegem, L., Duchateau, L., Van Hecke, L., et al. (2019). The use of equine chondrogenic-induced mesenchymal stem cells as a treatment for osteoarthritis: a randomised, doubleblinded, placebo-controlled proof-of-concept study. Equine Vet. J. 51, 787-794. doi: 10.1111/evj.13089

Brzezinski, A., Ghodbane, S. A., Patel, J. M., Perry, B. A., Gatt, C. J., and Dunn, M. G. (2017). (*) The ovine model for meniscus tissue engineering: considerations of anatomy, function, implantation, and evaluation. Tissue Eng. Part C Methods 23, 829-841. doi: 10.1089/ten.tec.2017.0192

Bullone, M., and Lavoie, J. P. (2015). Asthma "of horses and men"-how can equine heaves help us better understand human asthma immunopathology and its functional consequences? Mol. Immunol. 66, 97-105. doi: 10.1016/j.molimm. 2014.12.005

Bullone, M., and Lavoie, J. P. (2019). The equine asthma model of airway remodeling: from a veterinary to a human perspective. Cell Tissue Res. 380, 223-236. doi: 10.1007/s00441-019-03117-4

Burk, J., Berner, D., Brehm, W., Hillmann, A., Horstmeier, C., Josten, C., et al. (2016). Long-term cell tracking following local injection of mesenchymal stromal cells in the equine model of induced tendon disease. Cell Transplant. 25, 2199-2211. doi: 10.3727/096368916x692104

Cadby, J. A., David, F., Van De Lest, C., Bosch, G., Van Weeren, P. R., Snedeker, J. G., et al. (2013). Further characterisation of an experimental model of tendinopathy in the horse. Equine Vet. J. 45, 642-648. doi: 10.1111/evj.12035

Cahill, T. J., Ashrafian, H., and Watkins, H. (2013). Genetic cardiomyopathies causing heart failure. Circ. Res. 113, 660-675. doi: 10.1161/circresaha.113. 300282

Cai, B., Sun, S., Li, Z., Zhang, X., Ke, Y., Yang, J., et al. (2018). Application of CRISPR/Cas9 technologies combined with ipscs in the study and treatment of retinal degenerative diseases. Hum. Genet. 137, 679-688. doi: 10.1007/s00439018-1933-9

Campen, M. J., Tagaito, Y., Jenkins, T. P., Balbir, A., and O'donnell, C. P. (2005). Heart rate variability responses to hypoxic and hypercapnic exposures in different mouse strains. J. Appl. Physiol. 99, 807-813. doi: 10.1152/japplphysiol. 00039.2005

Campo, H., Baptista, P. M., Lopez-Perez, N., Faus, A., Cervello, I., and Simon, C. (2017). De- and recellularization of the pig uterus: a bioengineering pilot study. Biol. Reprod. 96, 34-45. doi: 10.1095/biolre/bio143396

Caniglia, C. J., Schramme, M. C., and Smith, R. K. (2012). The effect of intralesional injection of bone marrow derived mesenchymal stem cells and bone marrow supernatant on collagen fibril size in a surgical model of equine superficial digital flexor tendonitis. Equine Vet. J. 44, 587-593. doi: 10.1111/j.2042-3306. 2011.00514.x

Carpenter, J. E., and Hankenson, K. D. (2004). Animal models of tendon and ligament injuries for tissue engineering applications. Biomaterials 25, 17151722. doi: $10.1016 / \mathrm{s} 0142-9612(03) 00507-6$
Carvalho Ade, M., Badial, P. R., Alvarez, L. E., Yamada, A. L., Borges, A. S., Deffune, E., et al. (2013). Equine tendonitis therapy using mesenchymal stem cells and platelet concentrates: a randomized controlled trial. Stem Cell Res. Ther. 4:85. doi: $10.1186 /$ scrt236

Casanas, J., De La Torre, J., Soler, F., Garcia, F., Rodellar, C., Pumarola, M., et al. (2014). Peripheral nerve regeneration after experimental section in ovine radial and tibial nerves using synthetic nerve grafts, including expanded bone marrow mesenchymal cells: morphological and neurophysiological results. Injury 45(Suppl. 4), S2-S6.

Cattanach, B. M., Dukes-Mcewan, J., Wotton, P. R., Stephenson, H. M., and Hamilton, R. M. (2015). A pedigree-based genetic appraisal of Boxer Arvc and the role of the Striatin mutation. Vet. Rec. 176:492. doi: 10.1136/vr.102821

Chari, R. S., Collins, B. H., Magee, J. C., Dimaio, J. M., Kirk, A. D., Harland, R. C., et al. (1994). Brief report: treatment of hepatic failure with ex vivo pigliver perfusion followed by liver transplantation. N. Engl. J. Med. 331, 234-237. doi: 10.1056/nejm199407283310404

Cheng, K., Ibrahim, A., Hensley, M. T., Shen, D., Sun, B., Middleton, R., et al. (2014). Relative roles of Cd90 and c-kit to the regenerative efficacy of cardiosphere-derived cells in humans and in a mouse model of myocardial infarction. J. Am. Heart Assoc. 3:e001260.

Cheng, Y. J., Imperatore, G., Caspersen, C. J., Gregg, E. W., Albright, A. L., and Helmick, C. G. (2012). Prevalence of diagnosed arthritis and arthritisattributable activity limitation among adults with and without diagnosed diabetes: United States, 2008-2010. Diabetes Care 35, 1686-1691. doi: 10.2337/ dc12-0046

Chevrier, A., Nelea, M., Hurtig, M. B., Hoemann, C. D., and Buschmann, M. D. (2009). Meniscus structure in human, sheep, and rabbit for animal models of meniscus repair. J. Orthop. Res. 27, 1197-1203. doi: 10.1002/jor.20869

Chieppa, M. N., Perota, A., Corona, C., Grindatto, A., Lagutina, I., Vallino Costassa, E., et al. (2014). Modeling amyotrophic lateral sclerosis in hsod 1 transgenic swine. Neurodegener. Dis. 13, 246-254.

Chimenti, I., Smith, R. R., Li, T. S., Gerstenblith, G., Messina, E., Giacomello, A., et al. (2010). Relative roles of direct regeneration versus paracrine effects of human cardiosphere-derived cells transplanted into infarcted mice. Circ. Res. 106, 971-980. doi: 10.1161/circresaha.109.210682

Christopher, M. M. (2015). One health, one literature: weaving together veterinary and medical research. Sci. Transl. Med. 7:303fs36.

Chu, C. R., Szczodry, M., and Bruno, S. (2010). Animal models for cartilage regeneration and repair. Tissue Eng. Part B Rev. 16, 105-115. doi: 10.1089/ten. teb.2009.0452

Cipitria, A., Reichert, J. C., Epari, D. R., Saifzadeh, S., Berner, A., Schell, H., et al. (2013). Polycaprolactone scaffold and reduced rhbmp-7 dose for the regeneration of critical-sized defects in sheep tibiae. Biomaterials 34, 99609968. doi: 10.1016/j.biomaterials.2013.09.011

Cohen-Solal, M., Hay, E., and Funck-Brentano, T. (2012). Animal models in OA: a means to explore bone. Osteoporos. Int. 23(Suppl. 8), S853-S856.

Comerford, E. J., Smith, K., and Hayashi, K. (2011). Update on the aetiopathogenesis of canine cranial cruciate ligament disease. Vet. Comp. Orthop. Traumatol. 24, 91-98. doi: 10.3415/vcot-10-04-0055

Conboy, I. M., Conboy, M. J., Wagers, A. J., Girma, E. R., Weissman, I. L., and Rando, T. A. (2005). Rejuvenation of aged progenitor cells by exposure to a young systemic environment. Nature 433, 760-764. doi: 10.1038/nature03260

Condorelli, G., Borello, U., De Angelis, L., Latronico, M., Sirabella, D., Coletta, M., et al. (2001). Cardiomyocytes induce endothelial cells to trans-differentiate into cardiac muscle: implications for myocardium regeneration. Proc. Natl. Acad. Sci. U.S.A. 98, 10733-10738. doi: 10.1073/pnas.191217898

Cone, S. G., Warren, P. B., and Fisher, M. B. (2017). Rise of the pigs: utilization of the porcine model to study musculoskeletal biomechanics and tissue engineering during skeletal growth. Tissue Eng. Part C Methods 23, 763-780. doi: 10.1089/ten.tec.2017.0227

Connizzo, B. K., Yannascoli, S. M., and Soslowsky, L. J. (2013). Structure-function relationships of postnatal tendon development: a parallel to healing. Matrix Biol. 32, 106-116. doi: 10.1016/j.matbio.2013.01.007

Cook, J. L. (2010). Cranial cruciate ligament disease in dogs: biology versus biomechanics. Vet. Surg. 39, 270-277. doi: 10.1111/j.1532-950x.2010.00653.x

Cosmi, L., Liotta, F., and Annunziato, F. (2016). Th17 regulating lower airway disease. Curr. Opin. Allergy Clin. Immunol. 16, 1-6. doi: 10.1097/aci. 0000000000000227 
Couetil, L. L., Hoffman, A. M., Hodgson, J., Buechner-Maxwell, V., Viel, L., Wood, J. L., et al. (2007). Inflammatory airway disease of horses. J. Vet. Intern. Med. 21, 356-361. doi: 10.1111/j.1939-1676.2007.tb02975.x

Court, F. G., Laws, P. E., Morrison, C. P., Teague, B. D., Metcalfe, M. S., WemyssHolden, S. A., et al. (2004). Subtotal hepatectomy: a porcine model for the study of liver regeneration. J. Surg. Res. 116, 181-186. doi: 10.1016/j.jss.2003.08.007

Crovace, A., Lacitignola, L., Francioso, E., and Rossi, G. (2008). Histology and immunohistochemistry study of ovine tendon grafted with cBMSCs and BMMNCs after collagenase-induced tendinitis. Vet. Comp. Orthop. Traumatol. 21, 329-336. doi: 10.3415/vcot-07-05-0050

Crovace, A., Lacitignola, L., Rossi, G., and Francioso, E. (2010). Histological and immunohistochemical evaluation of autologous cultured bone marrow mesenchymal stem cells and bone marrow mononucleated cells in collagenaseinduced tendinitis of equine superficial digital flexor tendon. Vet. Med. Int. 2010:250978.

Cummings, I., George, S., Kelm, J., Schmidt, D., Emmert, M. Y., Weber, B., et al. (2012). Tissue-engineered vascular graft remodeling in a growing lamb model: expression of matrix metalloproteinases. Eur. J. Cardiothorac. Surg. 41, 167-172.

Dalgaard, L. (2015). Comparison of minipig, dog, monkey and human drug metabolism and disposition. J. Pharmacol. Toxicol. Methods 74, 80-92. doi: 10.1016/j.vascn.2014.12.005

Dalla Costa, E., Minero, M., Lebelt, D., Stucke, D., Canali, E., and Leach, M. C. (2014). Development of the Horse Grimace Scale (Hgs) as a pain assessment tool in horses undergoing routine castration. PLoS One 9:e92281. doi: 10.1371/ journal.pone.0092281

Daly, C. D., Ghosh, P., Zannettino, A. C. W., Badal, T., Shimmon, R., Jenkin, G., et al. (2018). Mesenchymal progenitor cells primed with pentosan polysulfate promote lumbar intervertebral disc regeneration in an ovine model of microdiscectomy. Spine J. 18, 491-506. doi: 10.1016/j.spinee.2017.10.008

De Bie, P., Van De Sluis, B., Burstein, E., Van De Berghe, P. V., Muller, P., Berger, R., et al. (2007). Distinct Wilson's disease mutations in Atp7B are associated with enhanced binding to Commd 1 and reduced stability of Atp7B. Gastroenterology 133, 1316-1326. doi: 10.1053/j.gastro.2007.07.020

Debrue, M., Hamilton, E., Joubert, P., Lajoie-Kadoch, S., and Lavoie, J. P. (2005). Chronic exacerbation of equine heaves is associated with an increased expression of interleukin-17 mRNA in bronchoalveolar lavage cells. Vet. Immunol. Immunopathol. 105, 25-31. doi: 10.1016/j.vetimm.2004.12.013

Delling, U., Brehm, W., Ludewig, E., Winter, K., and Julke, H. (2015a). Longitudinal evaluation of effects of intra-articular mesenchymal stromal cell administration for the treatment of osteoarthritis in an ovine model. Cell Transplant. 24, 2391-2407. doi: $10.3727 / 096368915 \times 686193$

Delling, U., Brehm, W., Metzger, M., Ludewig, E., Winter, K., and Julke, H. (2015b). In vivo tracking and fate of intra-articularly injected superparamagnetic iron oxide particle-labeled multipotent stromal cells in an ovine model of osteoarthritis. Cell Transplant. 24, 2379-2390. doi: 10.3727/096368914x685654

Denner, J. (2017). Can antiretroviral drugs be used to treat porcine endogenous retrovirus (PERV) Infection after Xenotransplantation? Viruses 9:213. doi: $10.3390 / \mathrm{v} 9080213$

Deponti, D., Di Giancamillo, A., Scotti, C., Peretti, G. M., and Martin, I. (2015). Animal models for meniscus repair and regeneration. J. Tissue Eng. Regen. Med. 9, 512-527. doi: 10.1002/term.1760

Deprés-Tremblay, G., Chevrier, A., Hurtig, M. B., Snow, M., Rodeo, S., and Buschmann, M. D. (2018). Freeze-dried chitosan-platelet-rich plasma implants for rotator cuff tear repair: pilot ovine studies. ACS Biomater. Sci. Eng. 4, 3737-3746. doi: 10.1021/acsbiomaterials.7b00354

Desando, G., Giavaresi, G., Cavallo, C., Bartolotti, I., Sartoni, F., Nicoli Aldini, N., et al. (2016). Autologous bone marrow concentrate in a sheep model of osteoarthritis: new perspectives for cartilage and meniscus repair. Tissue Eng. Part C Methods 22, 608-619. doi: 10.1089/ten.tec.2016.0033

Dias, I. R., Camassa, J. A., Bordelo, J. A., Babo, P. S., Viegas, C. A., Dourado, N., et al. (2018). Preclinical and translational studies in small ruminants (sheep and goat) as models for osteoporosis research. Curr. Osteoporos. Rep. 16, 182-197. doi: 10.1007/s11914-018-0431-2

Diogo, C. C., Camassa, J. A., Pereira, J. E., Costa, L. M. D., Filipe, V., Couto, P. A., et al. (2017). The use of sheep as a model for studying peripheral nerve regeneration following nerve injury: review of the literature. Neurol. Res. 39, 926-939. doi: 10.1080/01616412.2017.1331873
Divincenti, L. Jr., Westcott, R., and Lee, C. (2014). Sheep (Ovis aries) as a model for cardiovascular surgery and management before, during, and after cardiopulmonary bypass. J. Am. Assoc. Lab. Anim. Sci. 53, 439-448.

Douwes, J., Gibson, P., Pekkanen, J., and Pearce, N. (2002). Non-eosinophilic asthma: importance and possible mechanisms. Thorax 57, 643-648. doi: 10. 1136/thorax.57.7.643

Dowling, B. A., Dart, A. J., Hodgson, D. R., and Smith, R. K. (2000). Superficial digital flexor tendonitis in the horse. Equine Vet. J. 32, 369-378. doi: 10.2746/ 042516400777591138

Drosos, G. I., and Pozo, J. L. (2004). The causes and mechanisms of meniscal injuries in the sporting and non-sporting environment in an unselected population. Knee 11, 143-149. doi: 10.1016/s0968-0160(03)00105-4

Ducharme, N. G. (2004). "Surgery of the bovine digestive system," in Farm Animal Surgery, 1st Edn, ed. S. L. Fubini, and N.G. Ducharme (Philadelphia, PA: Elsevier).

Dudhia, J., Becerra, P., Valdes, M. A., Neves, F., Hartman, N. G., and Smith, R. K. (2015). In vivo imaging and tracking of technetium-99m labeled bone marrow mesenchymal stem cells in equine tendinopathy. J. Vis. Exp. 106:e52748.

Dutton, L. C., Church, S. A. V., Hodgkiss-Geere, H., Catchpole, B., Huggins, A., Dudhia, J., et al. (2018a). Cryopreservation of canine cardiosphere-derived cells: implications for clinical application. Cytometry A 93, 115-124. doi: 10.1002/ cyto.a.23186

Dutton, L. C., Dudhia, J., Catchpole, B., Hodgkiss-Geere, H., Werling, D., and Connolly, D. J. (2018b). Cardiosphere-derived cells suppress allogeneic lymphocytes by production of PGE2 acting via the EP4 receptor. Sci. Rep. 8:13351.

Dutton, L. C., Dudhia, J., Guest, D. J., and Connolly, D. J. (2019). Inducing pluripotency in the domestic cat (Felis catus). Stem Cells Dev. 28, 1299-1309. doi: $10.1089 /$ scd.2019.0142

Dziegielewska, K. M., Moller, J. E., Potter, A. M., Ek, J., Lane, M. A., and Saunders, N. R. (2000). Acute-phase cytokines IL-1beta and TNF-alpha in brain development. Cell Tissue Res. 299, 335-345. doi: 10.1007/s004419900157

Egenvall, A., Bonnett, B. N., and Haggstrom, J. (2006). Heart disease as a cause of death in insured Swedish dogs younger than 10 years of age. J. Vet. Intern. Med. 20, 894-903. doi: 10.1111/j.1939-1676.2006.tb01803.x

Elks, C. E., Perry, J. R., Sulem, P., Chasman, D. I., Franceschini, N., He, C., et al. (2010). Thirty new loci for age at menarche identified by a meta-analysis of genome-wide association studies. Nat. Genet. 42, 1077-1085.

Emmert, M. Y., Weber, B., Wolint, P., Frauenfelder, T., Zeisberger, S. M., Behr, L., et al. (2013). Intramyocardial transplantation and tracking of human mesenchymal stem cells in a novel intra-uterine pre-immune fetal sheep myocardial infarction model: a proof of concept study. PLoS One 8:e57759. doi: 10.1371/journal.pone.0057759

Entrican, G., Wattegedera, S. R., and Griffiths, D. J. (2015). Exploiting ovine immunology to improve the relevance of biomedical models. Mol. Immunol. 66, 68-77. doi: 10.1016/j.molimm.2014.09.002

Ericsson, A. C. (2019). The use of non-rodent model species in microbiota studies. Lab. Anim. 53, 259-270. doi: 10.1177/0023677219834593

Espinosa, P., Spriet, M., Sole, A., Walker, N. J., Vaughan, B., and Galuppo, L. D. (2016). Scintigraphic tracking of allogeneic mesenchymal stem cells in the distal limb after intra-arterial injection in standing horses. Vet. Surg. 45, 619-624. doi: $10.1111 /$ vsu. 12485

Fan, W., Wu, C., Miao, X., Liu, G., Saifzadeh, S., Sugiyama, S., et al. (2013). Biomaterial scaffolds in cartilage-subchondral bone defects influencing the repair of autologous articular cartilage transplants. J. Biomater. Appl. 27, 979989. doi: $10.1177 / 0885328211431310$

Favata, M., Beredjiklian, P. K., Zgonis, M. H., Beason, D. P., Crombleholme, T. M., Jawad, A. F., et al. (2006). Regenerative properties of fetal sheep tendon are not adversely affected by transplantation into an adult environment. J. Orthop. Res. 24, 2124-2132. doi: 10.1002/jor.20271

Favier, R. P., Spee, B., Fieten, H., Van Den Ingh, T. S., Schotanus, B. A., Brinkhof, B., et al. (2015). Aberrant expression of copper associated genes after copper accumulation in Commd1-deficient dogs. J. Trace Elem. Med. Biol. 29, 347-353. doi: 10.1016/j.jtemb.2014.06.007

Favier, R. P., Spee, B., Penning, L. C., and Rothuizen, J. (2011). Copper-induced hepatitis: the Commd1 deficient $\operatorname{dog}$ as a translational animal model for human chronic hepatitis. Vet. Q. 31, 49-60. doi: 10.1080/01652176.2011. 563146 
Favier, R. P., Spee, B., Schotanus, B. A., Van Den Ingh, T. S., Fieten, H., Brinkhof, B., et al. (2012). Commd1-deficient dogs accumulate copper in hepatocytes and provide a good model for chronic hepatitis and fibrosis. PLoS One 7:e42158. doi: 10.1371/journal.pone.0042158

Feng, C., Luo, X., He, N., Xia, H., Lv, X., Zhang, X., et al. (2018). Efficacy and persistence of allogeneic adipose-derived mesenchymal stem cells combined with hyaluronic acid in osteoarthritis after intra-articular injection in a sheep model. Tissue Eng. Part A 24, 219-233. doi: 10.1089/ten.tea.2017. 0039

Fernandes, M. B., Guimaraes, J. A., Casado, P. L., Cavalcanti Ados, S., Goncalves, N. N., Ambrosio, C. E., et al. (2014). The effect of bone allografts combined with bone marrow stromal cells on the healing of segmental bone defects in a sheep model. BMC Vet. Res. 10:36. doi: 10.1186/1746-6148-10-36

Ferris, D., Frisbie, D., Kisiday, J., and Mcilwraith, C. W. (2012). In vivo healing of meniscal lacerations using bone marrow-derived mesenchymal stem cells and fibrin glue. Stem Cells Int. 2012:691605.

Fieten, H., Gill, Y., Martin, A. J., Concilli, M., Dirksen, K., Van Steenbeek, F. G., et al. (2016). The Menkes and Wilson disease genes counteract in copper toxicosis in Labrador retrievers: a new canine model for copper-metabolism disorders. Dis. Model. Mech. 9, 25-38. doi: 10.1242/dmm.020263

Fieten, H., Penning, L. C., Leegwater, P. A., and Rothuizen, J. (2014). New canine models of copper toxicosis: diagnosis, treatment, and genetics. Ann. N. Y. Acad. Sci. 1314, 42-48. doi: 10.1111/nyas.12442

Flisikowska, T., Kind, A., and Schnieke, A. (2014). Genetically modified pigs to model human diseases. J. Appl. Genet. 55, 53-64. doi: 10.1007/s13353-0130182-9

Fonouni, H., Tahmasbi Rad, M., Esmaeilzadeh, M., Golriz, M., Majlesara, A., and Mehrabi, A. (2015). A simplified technique of pancreas transplantation in a porcine model. Eur. Surg. Res. 54, 24-33. doi: 10.1159/000367844

Forster, R., Bode, G., Ellegaard, L., and Van Der Laan, J. W. (2010). The RETHINK project-minipigs as models for the toxicity testing of new medicines and chemicals: an impact assessment. J. Pharmacol. Toxicol. Methods 62, 158-159.

Fortier, L. A., and Smith, R. K. (2008). Regenerative medicine for tendinous and ligamentous injuries of sport horses. Vet. Clin. North Am. Equine Pract. 24, 191-201. doi: 10.1016/j.cveq.2007.11.002

Fox, D. B., Warnock, J. J., Stoker, A. M., Luther, J. K., and Cockrell, M. (2010). Effects of growth factors on equine synovial fibroblasts seeded on synthetic scaffolds for avascular meniscal tissue engineering. Res. Vet. Sci. 88, 326-332. doi: 10.1016/j.rvsc.2009.07.015

Freeman, B. J., Kuliwaba, J. S., Jones, C. F., Shu, C. C., Colloca, C. J., Zarrinkalam, M. R., et al. (2016). Allogeneic mesenchymal precursor cells promote healing in postero-lateral annular lesions and improve indices of lumbar intervertebral disc degeneration in an ovine model. Spine 41, 1331-1339. doi: 10.1097/brs. 0000000000001528

Frey, M., Gruber, H., Happak, W., Girsch, W., Gruber, I., and Koller, R. (1990). Ipsilateral and cross-over elongation of the motor nerve by nerve grafting: an experimental study in sheep. Plast. Reconstr. Surg. 85, 77-89. doi: 10.1097/ 00006534-199001000-00014

Frisbie, D. D., Cross, M. W., and Mcilwraith, C. W. (2006). A comparative study of articular cartilage thickness in the stifle of animal species used in human preclinical studies compared to articular cartilage thickness in the human knee. Vet. Comp. Orthop. Traumatol. 19, 142-146. doi: 10.1055/s-0038-1632990

Fubini, S. L., and Ducharme, N. G. (eds) (2004). "Surgical considerations," in Farm Animal Surgery, 1st Edn (St. Louis, MO: Elsevier).

Fuentealba, I. C., and Aburto, E. M. (2003). Animal models of copper-associated liver disease. Comp. Hepatol. 2:5.

Fukashiro, S., Komi, P. V., Jarvinen, M., and Miyashita, M. (1995). In vivo Achilles tendon loading during jumping in humans. Eur. J. Appl. Physiol. Occup. Physiol. 71, 453-458. doi: 10.1007/bf00635880

Fukunishi, T., Best, C. A., Sugiura, T., Shoji, T., Yi, T., Udelsman, B., et al. (2016). Tissue-engineered small diameter arterial vascular grafts from cell-free Nanofiber PCL/chitosan scaffolds in a sheep model. PLoS One 11:e0158555. doi: 10.1371/journal.pone.0158555

Fullarton, A. C., Myles, L. M., Lenihan, D. V., Hems, T. E., and Glasby, M. A. (2001). Obstetric brachial plexus palsy: a comparison of the degree of recovery after repair of a C6 ventral root avulsion in newborn and adult sheep. Br. J. Plast. Surg. 54, 697-704. doi: 10.1054/bjps.2001.3700
Geburek, F., Lietzau, M., Beineke, A., Rohn, K., and Stadler, P. M. (2015). Effect of a single injection of autologous conditioned serum (Acs) on tendon healing in equine naturally occurring tendinopathies. Stem Cell Res. Ther. 6:126.

Geburek, F., Mundle, K., Conrad, S., Hellige, M., Walliser, U., Van Schie, H. T., et al. (2016). Tracking of autologous adipose tissue-derived mesenchymal stromal cells with in vivo magnetic resonance imaging and histology after intralesional treatment of artificial equine tendon lesions-a pilot study. Stem Cell Res. Ther. 7:21.

Glasby, M. A., Mountain, R. E., and Murray, J. A. (1993). Repair of the facial nerve using freeze-thawed muscle autografts. A surgical model in the sheep. Arch. Otolaryngol. Head Neck Surg. 119, 461-465. doi: 10.1001/archotol.1993. 01880160109018

Gleerup, K. B., Forkman, B., Lindegaard, C., and Andersen, P. H. (2015). An equine pain face. Vet. Anaesth. Analg. 42, 103-114.

Godwin, E. E., Young, N. J., Dudhia, J., Beamish, I. C., and Smith, R. K. (2012). Implantation of bone marrow-derived mesenchymal stem cells demonstrates improved outcome in horses with overstrain injury of the superficial digital flexor tendon. Equine Vet. J. 44, 25-32. doi: 10.1111/j.2042-3306.2011. 00363.x

Goldberg, A. J., Zaidi, R., Brooking, D., Kim, L., Korda, M., Masci, L., et al. (2018). Autologous Stem Cells in Achilles Tendinopathy (ASCAT): protocol for a phase IIA, single-centre, proof-of-concept study. BMJ Open 8:e021600.

Gonzalez-Fernandez, M. L., Perez-Castrillo, S., Sanchez-Lazaro, J. A., PrietoFernandez, J. G., Lopez-Gonzalez, M. E., Lobato-Perez, S., et al. (2016). Assessment of regeneration in meniscal lesions by use of mesenchymal stem cells derived from equine bone marrow and adipose tissue. Am. J. Vet. Res. 77, 779-788. doi: 10.2460/ajvr.77.7.779

Goodship, A. E., Birch, H. L., and Wilson, A. M. (1994). The pathobiology and repair of tendon and ligament injury. Vet. Clin. North Am. Equine Pract. 10, 323-349. doi: 10.1016/s0749-0739(17)30359-0

Gotterbarm, T., Breusch, S. J., Schneider, U., and Jung, M. (2008). The minipig model for experimental chondral and osteochondral defect repair in tissue engineering: retrospective analysis of 180 defects. Lab. Anim. 42, 71-82. doi: 10.1258/la.2007.06029e

Govoni, K. E. (2015). HORSE SPECIES SYMPOSIUM: use of mesenchymal stem cells in fracture repair in horses. J. Anim. Sci. 93, 871-878.

Graubner, C., Gerber, V., Doherr, M., and Spadavecchia, C. (2011). Clinical application and reliability of a post abdominal surgery pain assessment scale (PASPAS) in horses. Vet. J. 188, 178-183. doi: 10.1016/j.tvjl.2010.04.029

Griesemer, A., Yamada, K., and Sykes, M. (2014). Xenotransplantation: immunological hurdles and progress toward tolerance. Immunol. Rev. 258, 241-258. doi: 10.1111/imr.12152

Gruchenberg, K., Ignatius, A., Friemert, B., Von Lubken, F., Skaer, N., Gellynck, K., et al. (2015). In vivo performance of a novel silk fibroin scaffold for partial meniscal replacement in a sheep model. Knee Surg. Sports Traumatol. Arthrosc. 23, 2218-2229. doi: 10.1007/s00167-014-3009-2

Guest, D. J., Smith, M. R., and Allen, W. R. (2008). Monitoring the fate of autologous and allogeneic mesenchymal progenitor cells injected into the superficial digital flexor tendon of horses: preliminary study. Equine Vet. J. 40, 178-181. doi: 10.2746/042516408x276942

Gugjoo, M. B., Fazili, M. R., Gayas, M. A., Ahmad, R. A., and Dhama, K. (2019). Animal mesenchymal stem cell research in cartilage regenerative medicine - a review. Vet. Q. 39, 95-120. doi: 10.1080/01652176.2019.1643051

Gupte, C. M., Bull, A. M., Murray, R., and Amis, A. A. (2007). Comparative anatomy of the meniscofemoral ligament in humans and some domestic mammals. Anat. Histol. Embryol. 36, 47-52. doi: 10.1111/j.1439-0264.2006. 00718.x

Hager, C., Biernot, S., Buettner, M., Glage, S., Keubler, L. M., Held, N., et al. (2017). The Sheep Grimace Scale as an indicator of post-operative distress and pain in laboratory sheep. PLoS One 12:e0175839. doi: 10.1371/journal.pone.0175839

Haywood, S., Muller, T., Muller, W., Heinz-Erian, P., Tanner, M. S., and Ross, G. (2001). Copper-associated liver disease in North Ronaldsay sheep: a possible animal model for non-Wilsonian hepatic copper toxicosis of infancy and childhood. J. Pathol. 195, 264-269. doi: 10.1002/path.930

Haywood, S., Rutgers, H. C., and Christian, M. K. (1988). Hepatitis and copper accumulation in Skye terriers. Vet. Pathol. 25, 408-414. doi: 10.1177/ 030098588802500602 
He, B., Musk, G. C., Mou, L., De Boer, B., Delriviere, L., and Hamdorf, J. (2013). Laparoscopic surgery for orthotopic kidney transplant in the pig model. J. Surg. Res. 184, 1096-1101. doi: 10.1016/j.jss.2013.03.015

Hems, T. E., Clutton, R. E., and Glasby, M. A. (1994). Repair of avulsed cervical nerve roots. An experimental study in sheep. J. Bone Joint Surg. Br. 76, 818-823. doi: 10.1302/0301-620x.76b5.8083277

Hems, T. E., and Glasby, M. A. (1992). Repair of cervical nerve roots proximal to the root ganglia. An experimental study in sheep. J. Bone Joint Surg. Br. 74, 918-922. doi: 10.1302/0301-620x.74b6.1447258

Hensley, M. T., De Andrade, J., Keene, B., Meurs, K., Tang, J., Wang, Z., et al. (2015). Cardiac regenerative potential of cardiosphere-derived cells from adult dog hearts. J. Cell Mol. Med. 19, 1805-1813. doi: 10.1111/jcmm. 12585

Hensley, M. T., Tang, J., Woodruff, K., Defrancesco, T., Tou, S., Williams, C. M., et al. (2017). Intracoronary allogeneic cardiosphere-derived stem cells are safe for use in dogs with dilated cardiomyopathy. J. Cell. Mol. Med. 21, 1503-1512. doi: $10.1111 / \mathrm{jcmm} .13077$

Herdrich, B. J., Danzer, E., Davey, M. G., Bermudez, D. M., Radu, A., Zhang, L., et al. (2010). Fetal tendon wound size modulates wound gene expression and subsequent wound phenotype. Wound Repair Regen. 18, 543-549. doi: 10.1111/j.1524-475x.2010.00615.x

Heron, M. (2016). Deaths: leading causes for 2014. Natl. Vital Stat. Rep. 65, 1-96.

Herszberg, B., Ramos-Barbon, D., Tamaoka, M., Martin, J. G., and Lavoie, J. P. (2006). Heaves, an asthma-like equine disease, involves airway smooth muscle remodeling. J. Allergy Clin. Immunol. 118, 382-388. doi: 10.1016/j.jaci.2006. 03.044

Hoffmann, G., Van Den Ingh, T. S., Bode, P., and Rothuizen, J. (2006). Copperassociated chronic hepatitis in Labrador Retrievers. J. Vet. Intern. Med. 20, 856-861. doi: 10.1111/j.1939-1676.2006.tb01798.x

Hopper, N., Wardale, J., Brooks, R., Power, J., Rushton, N., and Henson, F. (2015). Peripheral blood mononuclear cells enhance cartilage repair in in vivo osteochondral defect model. PLoS One 10:e0133937. doi: 10.1371/journal.pone. 0133937

Hotchkiss, J. W., Reid, S. W., and Christley, R. M. (2007). A survey of horse owners in Great Britain regarding horses in their care. Part 2: Risk factors for recurrent airway obstruction. Equine Vet. J. 39, 301-308. doi: 10.2746/042516407x18 0129

Houtgraaf, J. H., De Jong, R., Kazemi, K., De Groot, D., Van Der Spoel, T. I., Arslan, F., et al. (2013). Intracoronary infusion of allogeneic mesenchymal precursor cells directly after experimental acute myocardial infarction reduces infarct size, abrogates adverse remodeling, and improves cardiac function. Circ. Res. 113, 153-166. doi: 10.1161/circresaha.112.300730

Huke, S., and Knollmann, B. C. (2010). Increased myofilament Ca2+-sensitivity and arrhythmia susceptibility. J. Mol. Cell. Cardiol. 48, 824-833. doi: 10.1016/j. yjmcc.2010.01.011

Hurtig, M. B., Buschmann, M. D., Fortier, L. A., Hoemann, C. D., Hunziker, E. B., Jurvelin, J. S., et al. (2011). Preclinical studies for cartilage repair: recommendations from the international cartilage repair society. Cartilage 2, 137-152. doi: 10.1177/1947603511401905

Hurtig, M. B., Novak, K., Mcpherson, R., Mcfadden, S., Mcgann, L. E., Mul Drew, K., et al. (1998). Osteochondral dowel transplantation for repair of focal defects in the knee: an outcome study using an ovine model. Vet. Surg. 27, 5-16. doi: 10.1111/j.1532-950x.1998.tb00092.x

Husser, D., Ueberham, L., Jacob, J., Heuer, D., Riedel-Heller, S., Walker, J., et al. (2018). Prevalence of clinically apparent hypertrophic cardiomyopathy in Germany-An analysis of over 5 million patients. PLoS One 13:e0196612. doi: 10.1371/journal.pone. 0196612

Iacopetti, I., Perazzi, A., Martinello, T., Gemignani, F., and Patruno, M. (2020). Hyaluronic acid, Manuka honey and Acemannan gel: wound-specific applications for skin lesions. Res. Vet. Sci. 129, 82-89. doi: 10.1016/j.rvsc.2020. 01.009

Inesi, G. (2017). Molecular features of copper binding proteins involved in copper homeostasis. IUBMB Life 69, 211-217. doi: 10.1002/iub.1590

Ingenito, E. P., Tsai, L., Murthy, S., Tyagi, S., Mazan, M., and Hoffman, A. (2012). Autologous lung-derived mesenchymal stem cell transplantation in experimental emphysema. Cell Transplant. 21, 175-189. doi: 10.3727/ 096368910x550233

Iwaniec, T. (2008). "Animal models for osteoporosis," in Osteoporosis, 3rd Edn, eds R. Marcus, D. Feldman, D. Nelson, and C. Rosen (Amsterdam: Elsevier).
Jackson, S. J., Andrews, N., Ball, D., Bellantuono, I., Gray, J., Hachoumi, L., et al. (2017). Does age matter? The impact of rodent age on study outcomes. Lab. Anim. 51, 160-169. doi: 10.1177/0023677216653984

Jarvinen, T. A., Kannus, P., Maffulli, N., and Khan, K. M. (2005). Achilles tendon disorders: etiology and epidemiology. Foot Ankle Clin. 10, 255-266. doi: 10. 1016/j.fcl.2005.01.013

Jeanblanc, C., Goodrich, A. D., Colletti, E., Mokhtari, S., Porada, C. D., Zanjani, E. D., et al. (2014). Temporal definition of haematopoietic stem cell niches in a large animal model of in utero stem cell transplantation. Br. J. Haematol. 166, 268-278. doi: 10.1111/bjh.12870

Jeong, Y. H., Park, C. H., Jang, G. H., Jeong, Y. I., Hwang, I. S., Jeong, Y. W., et al. (2013). Production of multiple transgenic Yucatan miniature pigs expressing human complement regulatory factors, human CD55, CD59, and H-transferase genes. PLoS One 8:e63241. doi: 10.1371/journal.pone.0063241

Jiang, Y., Xie, M., Chen, W., Talbot, R., Maddox, J. F., Faraut, T., et al. (2014). The sheep genome illuminates biology of the rumen and lipid metabolism. Science $344,1168-1173$.

Johnson, V. L., and Hunter, D. J. (2014). The epidemiology of osteoarthritis. Best Pract. Res. Clin. Rheumatol. 28, 5-15.

Johnston, P. V., Sasano, T., Mills, K., Evers, R., Lee, S. T., Smith, R. R., et al. (2009). Engraftment, differentiation, and functional benefits of autologous cardiosphere-derived cells in porcine ischemic cardiomyopathy. Circulation 120, 1075-1083. doi: 10.1161/circulationaha.108.816058

Julke, H., Veit, C., Ribitsch, I., Brehm, W., Ludewig, E., and Delling, U. (2015). Comparative labeling of equine and ovine multipotent stromal cells with superparamagnetic iron oxide particles for magnetic resonance imaging in vitro. Cell Transplant. 24, 1111-1125. doi: 10.3727/096368913x675737

Kahn, D., Hickman, R., Terblanche, J., and Von Sommoggy, S. (1988). Partial hepatectomy and liver regeneration in pigs-the response to different resection sizes. J. Surg. Res. 45, 176-180. doi: 10.1016/0022-4804(88)90062-5

Kajbafzadeh, A. M., Khorramirouz, R., Nabavizadeh, B., Ladi Seyedian, S. S., Akbarzadeh, A., Heidari, R., et al. (2019). Whole organ sheep kidney tissue engineering and in vivo transplantation: effects of perfusion-based decellularization on vascular integrity. Mater. Sci. Eng. C Mater. Biol. Appl. 98, 392-400. doi: 10.1016/j.msec.2019.01.018

Kang, N. V., Morritt, D., Pendegrass, C., and Blunn, G. (2013). Use of ITAP implants for prosthetic reconstruction of extra-oral craniofacial defects. J. Plast. Reconstr. Aesthet. Surg. 66, 497-505. doi: 10.1016/j.bjps.2012.11.036

Kang, N. V., Pendegrass, C., Marks, L., and Blunn, G. (2010). Osseocutaneous integration of an intraosseous transcutaneous amputation prosthesis implant used for reconstruction of a transhumeral amputee: case report. J. Hand Surg. Am. 35, 1130-1134. doi: 10.1016/j.jhsa.2010.03.037

Karlin, W. M., Stewart, A. A., Durgam, S. S., Naughton, J. F., O'dell-Anderson, K. J., and Stewart, M. C. (2011). Evaluation of experimentally induced injury to the superficial digital flexor tendon in horses by use of low-field magnetic resonance imaging and ultrasonography. Am. J. Vet. Res. 72, 791-798. doi: 10.2460/ajvr.72.6.791

Kim, B. E., Nevitt, T., and Thiele, D. J. (2008). Mechanisms for copper acquisition, distribution and regulation. Nat. Chem. Biol. 4, 176-185. doi: 10.1038/ nchembio.72

Kim, H. K., Moran, M. E., and Salter, R. B. (1991). The potential for regeneration of articular cartilage in defects created by chondral shaving and subchondral abrasion. An experimental investigation in rabbits. J. Bone Joint Surg. Am. 73, 1301-1315. doi: 10.2106/00004623-199173090-00004

Kim, J., Zanjani, E. D., Jeanblanc, C. M., Goodrich, A. D., and Hematti, P. (2013). Generation of CD34+ cells from human embryonic stem cells using a clinically applicable methodology and engraftment in the fetal sheep model. Exp. Hematol. 41, 749-758.e5. doi: 10.1016/j.exphem.2013.04.003

Kirschvink, N., and Reinhold, P. (2008). Use of alternative animals as asthma models. Curr. Drug Targets 9, 470-484. doi: 10.2174/138945008784533525

Kisiday, J. D., Mcilwraith, C. W., Rodkey, W. G., Frisbie, D. D., and Steadman, J. R. (2012). Effects of platelet-rich plasma composition on anabolic and catabolic activities in equine cartilage and meniscal explants. Cartilage 3, 245-254. doi: $10.1177 / 1947603511433181$

Kluin, J., Talacua, H., Smits, A. I., Emmert, M. Y., Brugmans, M. C., Fioretta, E. S., et al. (2017). In situ heart valve tissue engineering using a bioresorbable elastomeric implant - From material design to 12 months follow-up in sheep. Biomaterials 125, 101-117. doi: 10.1016/j.biomaterials.2017.02.007 
Klukowska-Rotzler, J., Swinburne, J. E., Drogemuller, C., Dolf, G., Janda, J., Leeb, T., et al. (2012). The interleukin 4 receptor gene and its role in recurrent airway obstruction in Swiss Warmblood horses. Anim. Genet. 43, 450-453. doi: 10.1111/j.1365-2052.2011.02277.x

Klymiuk, N., Blutke, A., Graf, A., Krause, S., Burkhardt, K., Wuensch, A., et al. (2013). Dystrophin-deficient pigs provide new insights into the hierarchy of physiological derangements of dystrophic muscle. Hum. Mol. Genet. 22, 4368 4382. doi: $10.1093 / \mathrm{hmg} / \mathrm{ddt} 287$

Kocyildirim, E., Cardenes, N., Ting, A., Caceres, E., Bermudez, C., and Rojas, M. (2017). The use of GMP-produced bone marrow-derived stem cells in combination with extracorporeal membrane oxygenation in ARDS: an animal model. ASAIO J. 63, 324-332. doi: 10.1097/mat.0000000000000566

Kol, A., Arzi, B., Athanasiou, K. A., Farmer, D. L., Nolta, J. A., Rebhun, R. B., et al. (2015). Companion animals: translational scientist's new best friends. Sci. Transl. Med. 7:308s21.

Kon, E., Muraglia, A., Corsi, A., Bianco, P., Marcacci, M., Martin, I., et al. (2000). Autologous bone marrow stromal cells loaded onto porous hydroxyapatite ceramic accelerate bone repair in critical-size defects of sheep long bones. J. Biomed. Mater. Res. 49, 328-337. doi: 10.1002/(sici)1097-4636(20000305)49: $3<328$ ::aid-jbm5>3.0.co;2-q

Koobatian, M. T., Row, S., Smith, R. J. Jr., Koenigsknecht, C., Andreadis, S. T., and Swartz, D. D. (2016). Successful endothelialization and remodeling of a cell-free small-diameter arterial graft in a large animal model. Biomaterials 76, 344-358. doi: 10.1016/j.biomaterials.2015.10.020

Krupkova, O., Smolders, L., Wuertz-Kozak, K., Cook, J., and Pozzi, A. (2018). The pathobiology of the meniscus: a comparison between the human and dog. Front. Vet. Sci. 5:73. doi: 10.3389/fvets.2018.00073

Kuroki, K., Cook, C. R., and Cook, J. L. (2011). Subchondral bone changes in three different canine models of osteoarthritis. Osteoarthritis Cartilage 19, 1142-1149. doi: 10.1016/j.joca.2011.06.007

Kuyinu, E. L., Narayanan, G., Nair, L. S., and Laurencin, C. T. (2016). Animal models of osteoarthritis: classification, update, and measurement of outcomes. J. Orthop. Surg. Res. 11:19.

Kuypers, E., Ophelders, D., Jellema, R. K., Kunzmann, S., Gavilanes, A. W., and Kramer, B. W. (2012). White matter injury following fetal inflammatory response syndrome induced by chorioamnionitis and fetal sepsis: lessons from experimental ovine models. Early Hum. Dev. 88, 931-936. doi: 10.1016/j. earlhumdev.2012.09.011

Lacitignola, L., Crovace, A., Rossi, G., and Francioso, E. (2008). Cell therapy for tendinitis, experimental and clinical report. Vet. Res. Commun. 32(Suppl. 1), S33-S38.

Lai, L., Kolber-Simonds, D., Park, K. W., Cheong, H. T., Greenstein, J. L., Im, G. S., et al. (2002). Production of alpha-1,3-galactosyltransferase knockout pigs by nuclear transfer cloning. Science 295, 1089-1092. doi: 10.1126/science.10 68228

Lairmore, M. D., and Khanna, C. (2014). Naturally occurring diseases in animals: contributions to translational medicine. ILAR J. 55, 1-3. doi: 10.1093/ilar/ ilu022

Lampropoulou-Adamidou, K., Lelovas, P., Karadimas, E. V., Liakou, C., Triantafillopoulos, I. K., Dontas, I., et al. (2014). Useful animal models for the research of osteoarthritis. Eur. J. Orthop. Surg. Traumatol. 24, 263-271.

Lange-Consiglio, A., Stucchi, L., Zucca, E., Lavoie, J. P., Cremonesi, F., and Ferrucci, F. (2019). Insights into animal models for cell-based therapies in translational studies of lung diseases: Is the horse with naturally occurring asthma the right choice? Cytotherapy 21, 525-534. doi: 10.1016/j.jcyt.2019. 02.010

Larson, G., Karlsson, E. K., Perri, A., Webster, M. T., Ho, S. Y., Peters, J., et al. (2012). Rethinking dog domestication by integrating genetics, archeology, and biogeography. Proc. Natl. Acad. Sci. U.S.A. 109, 8878-8883. doi: 10.1073/pnas. 1203005109

Lavoie, J. P., Maghni, K., Desnoyers, M., Taha, R., Martin, J. G., and Hamid, Q. A. (2001). Neutrophilic airway inflammation in horses with heaves is characterized by a Th2-type cytokine profile. Am. J. Respir. Crit. Care Med. 164, 1410-1413. doi: 10.1164/ajrccm.164.8.2012091

Leclere, M., Lavoie-Lamoureux, A., Gelinas-Lymburner, E., David, F., Martin, J. G., and Lavoie, J. P. (2011). Effect of antigenic exposure on airway smooth muscle remodeling in an equine model of chronic asthma. Am. J. Respir. Cell Mol. Biol. 45, 181-187. doi: $10.1165 / \mathrm{rcmb} .2010-0300 \mathrm{oc}$
Lelovas, P. P., Xanthos, T. T., Thoma, S. E., Lyritis, G. P., and Dontas, I. A. (2008). The laboratory rat as an animal model for osteoporosis research. Comp. Med. 58, 424-430.

Li, T. S., Cheng, K., Malliaras, K., Smith, R. R., Zhang, Y., Sun, B., et al. (2012). Direct comparison of different stem cell types and subpopulations reveals superior paracrine potency and myocardial repair efficacy with cardiospherederived cells. J. Am. Coll. Cardiol. 59, 942-953. doi: 10.1016/j.jacc.2011. 11.029

Li, Y., Chen, S. K., Li, L., Qin, L., Wang, X. L., and Lai, Y. X. (2015). Bone defect animal models for testing efficacy of bone substitute biomaterials. J. Orthop. Transl. 3, 95-104. doi: 10.1016/j.jot.2015.05.002

Liebsch, C., Bucan, V., Menger, B., Kohne, F., Waldmann, K. H., Vaslaitis, D., et al. (2018). Preliminary investigations of spider silk in wounds in vivo - Implications for an innovative wound dressing. Burns 44, 1829-1838. doi: 10.1016/j.burns. 2018.03.016

Liechty, K. W., Mackenzie, T. C., Shaaban, A. F., Radu, A., Moseley, A. M., Deans, R., et al. (2000). Human mesenchymal stem cells engraft and demonstrate sitespecific differentiation after in utero transplantation in sheep. Nat. Med. 6, 1282-1286. doi: 10.1038/81395

Lindblad-Toh, K., Wade, C. M., Mikkelsen, T. S., Karlsson, E. K., Jaffe, D. B., Kamal, M., et al. (2005). Genome sequence, comparative analysis and haplotype structure of the domestic dog. Nature 438, 803-819.

Little, C. B., and Hunter, D. J. (2013). Post-traumatic osteoarthritis: from mouse models to clinical trials. Nat. Rev. Rheumatol. 9, 485-497. doi: 10.1038/ nrrheum.2013.72

Little, C. B., and Zaki, S. (2012). What constitutes an "animal model of osteoarthritis"-the need for consensus? Osteoarthritis Cartilage 20, 261-267. doi: 10.1016/j.joca.2012.01.017

Liu, J. Z., Van Sommeren, S., Huang, H., Ng, S. C., Alberts, R., Takahashi, A., et al. (2015). Association analyses identify 38 susceptibility loci for inflammatory bowel disease and highlight shared genetic risk across populations. Nat. Genet. 47, 979-986. doi: 10.1038/ng.3359

Lizarraga, I., and Chambers, J. P. (2012). Use of analgesic drugs for pain management in sheep. N. Z. Vet. J. 60, 87-94. doi: 10.1080/00480169.2011. 642772

Lo Monaco, M., Merckx, G., Ratajczak, J., Gervois, P., Hilkens, P., Clegg, P., et al. (2018). Stem cells for cartilage repair: preclinical studies and insights in translational animal models and outcome measures. Stem Cells Int. 2018:9079538.

Lorbach, O., Baums, M. H., Kostuj, T., Pauly, S., Scheibel, M., Carr, A., et al. (2015). Advances in biology and mechanics of rotator cuff repair. Knee Surg. Sports Traumatol. Arthrosc. 23, 530-541.

Lovicu, M., Dessi, V., Lepori, M. B., Zappu, A., Zancan, L., Giacchino, R., et al. (2006). The canine copper toxicosis gene Murr1 is not implicated in the pathogenesis of Wilson disease. J. Gastroenterol. 41, 582-587. doi: 10.1007/ s00535-006-1807-0

Madden, J. C., Hewitt, M., Przybylak, K., Vandebriel, R. J., Piersma, A. H., and Cronin, M. T. (2012). Strategies for the optimisation of in vivo experiments in accordance with the 3Rs philosophy. Regul. Toxicol. Pharmacol. 63, 140-154. doi: 10.1016/j.yrtph.2012.03.010

Maffulli, N. (1999). Rupture of the Achilles tendon. J. Bone Joint. Surg. Am. 81, 1019-1036.

Maher, R. L., Barbash, S. M., Lynch, D. V., and Swoap, S. J. (2015). Group housing and nest building only slightly ameliorate the cold stress of typical housing in female C57bl/6J mice. Am. J. Physiol. Regul. Integr. Comp. Physiol. 308, R1070-R1079.

Makkar, R. R., Smith, R. R., Cheng, K., Malliaras, K., Thomson, L. E., Berman, D., et al. (2012). Intracoronary cardiosphere-derived cells for heart regeneration after myocardial infarction (CADUCEUS): a prospective, randomised phase 1 trial. Lancet 379, 895-904. doi: 10.1016/s0140-6736(12)60195-0

Malda, J., Benders, K. E., Klein, T. J., De Grauw, J. C., Kik, M. J., Hutmacher, D. W., et al. (2012). Comparative study of depth-dependent characteristics of equine and human osteochondral tissue from the medial and lateral femoral condyles. Osteoarthritis Cartilage 20, 1147-1151. doi: 10.1016/j.joca.2012.06.005

Malliaras, K., Li, T. S., Luthringer, D., Terrovitis, J., Cheng, K., Chakravarty, T., et al. (2012). Safety and efficacy of allogeneic cell therapy in infarcted rats transplanted with mismatched cardiosphere-derived cells. Circulation 125, 100-112. doi: 10.1161/circulationaha.111.042598 
Malliaras, K., Makkar, R. R., Smith, R. R., Cheng, K., Wu, E., Bonow, R. O., et al. (2014). Intracoronary cardiosphere-derived cells after myocardial infarction: evidence of therapeutic regeneration in the final 1-year results of the CADUCEUS trial (CArdiosphere-Derived aUtologous stem CElls to reverse ventricUlar dySfunction). J. Am. Coll. Cardiol. 63, 110-122.

Marfe, G., Rotta, G., De Martino, L., Tafani, M., Fiorito, F., Di Stefano, C., et al. (2012). A new clinical approach: use of blood-derived stem cells (BDSCs) for superficial digital flexor tendon injuries in horses. Life Sci. 90, 825-830. doi: 10.1016/j.lfs.2012.03.004

Marijnissen, A. C., Van Roermund, P. M., Tekoppele, J. M., Bijlsma, J. W., and Lafeber, F. P. (2002). The canine 'groove' model, compared with the ACLT model of osteoarthritis. Osteoarthritis Cartilage 10, 145-155. doi: 10.1053/joca. 2001.0491

Mariscal, A., Caldarone, L., Tikkanen, J., Nakajima, D., Chen, M., Yeung, J., et al. (2018). Pig lung transplant survival model. Nat. Protoc. 13, 1814-1828. doi: 10.1038/s41596-018-0019-4

Marlovits, S., Singer, P., Zeller, P., Mandl, I., Haller, J., and Trattnig, S. (2006). Magnetic resonance observation of cartilage repair tissue (MOCART) for the evaluation of autologous chondrocyte transplantation: determination of interobserver variability and correlation to clinical outcome after 2 years. Eur. J. Radiol. 57, 16-23. doi: 10.1016/j.ejrad.2005.08.007

Maron, B. J., and Fox, P. R. (2015). Hypertrophic cardiomyopathy in man and cats. J. Vet. Cardiol. 17(Suppl. 1), S6-S9.

Maron, B. J., Gardin, J. M., Flack, J. M., Gidding, S. S., Kurosaki, T. T., and Bild, D. E. (1995). Prevalence of hypertrophic cardiomyopathy in a general population of young adults. Echocardiographic analysis of 4111 subjects in the CARDIA Study. Coronary Artery Risk Development in (Young) Adults. Circulation 92, 785-789. doi: 10.1161/01.cir.92.4.785

Marston, S. B. (2011). How do mutations in contractile proteins cause the primary familial cardiomyopathies? J. Cardiovasc. Transl. Res. 4, 245-255. doi: 10.1007/ s12265-011-9266-2

Martin, J., Sarai, K., Yoshitake, M., Haberstroh, J., Takahashi, N., Lutter, G., et al. (1999). Successful orthotopic pig heart transplantation from non-heart-beating donors. J. Heart Lung Transplant. 18, 597-606. doi: 10.1016/s1053-2498(98) 00017-5

Martinello, T., Bronzini, I., Perazzi, A., Testoni, S., De Benedictis, G. M., Negro, A., et al. (2013). Effects of in vivo applications of peripheral blood-derived mesenchymal stromal cells (PB-MSCs) and platlet-rich plasma (PRP) on experimentally injured deep digital flexor tendons of sheep. J. Orthop. Res. 31, 306-314. doi: 10.1002/jor.22205

Martinello, T., Gomiero, C., Perazzi, A., Iacopetti, I., Gemignani, F., DeBenedictis, G. M., et al. (2018). Allogeneic mesenchymal stem cells improve the wound healing process of sheep skin. BMC Vet. Res. 14, 1-9. doi: 10.1186/s12917-018-1527-8

Martines, E., Brun, P., Cavazzana, R., Cordaro, L., Zuin, M., Martinello, T., et al. (2020). Wound healing improvement in large animals using an indirect helium plasma treatment. Clin. Plasma Med. 17-18:100095. doi: 10.1016/j.cpme.2020. 100095

Marubayashi, S., Asahara, T., Ono, E., Tashiro, H., Okugawa, K., Okimoto, T., et al. (1995). Auxiliary heterotopic partial liver transplantation in pigs with acute liver failure. Surg. Today 25, 429-432. doi: 10.1007/bf00311820

Matsuyama, T., Midha, R., Mackinnon, S. E., Munro, C. A., Wong, P. Y., and Ang, L. C. (2000). Long nerve allografts in sheep with Cyclosporin A immunosuppression. J. Reconstr. Microsurg. 16, 219-225.

Mausberg, T. B., Wess, G., Simak, J., Keller, L., Drogemuller, M., Drogemuller, C., et al. (2011). A locus on chromosome 5 is associated with dilated cardiomyopathy in Doberman Pinschers. PLoS One 6:e20042. doi: 10.1371/ journal.pone. 0020042

Mazzone, L., Moehrlen, U., Ochsenbein-Kolble, N., Pontiggia, L., Biedermann, T., Reichmann, E., et al. (2020). Bioengineering and in utero transplantation of fetal skin in the sheep model: a crucial step towards clinical application in human fetal spina bifida repair. J. Tissue Eng. Regen. Med. 14, 58-65. doi: 10.1002/term.2963

Mcanulty, P., Dayan, A., Ganderup, N.-C., Hastings, K., Turk, J., and Laughlin, M. (2011). The Minipig in Biomedical Research. Boca Raton, FL: Taylor \& Francis.

Mccoy, A. M. (2015). Animal models of osteoarthritis: comparisons and key considerations. Vet. Pathol. 52, 803-818. doi: 10.1177/03009858155 88611
Mcduffee, L. A., Pack, L., Lores, M., Wright, G. M., Esparza-Gonzalez, B., and Masaoud, E. (2012). Osteoprogenitor cell therapy in an equine fracture model. Vet. Surg. 41, 773-783. doi: 10.1111/j.1532-950x.2012.01024.x

Mcgovern, J. A., Griffin, M., and Hutmacher, D. W. (2018). Animal models for bone tissue engineering and modelling disease. Dis. Model. Mech. 11:dmm033084. doi: $10.1242 / \mathrm{dmm} .033084$

Mcilwraith, C. W., Fortier, L. A., Frisbie, D. D., and Nixon, A. J. (2011). Equine Models of Articular Cartilage Repair. Cartilage 2, 317-326. doi: 10.1177/ 1947603511406531

Mcilwraith, C. W., Frisbie, D. D., and Kawcak, C. E. (2012). The horse as a model of naturally occurring osteoarthritis. Bone Joint Res. 1, 297-309. doi: 10.1302/ 2046-3758.111.2000132

Mcilwraith, C. W., Frisbie, D. D., Kawcak, C. E., Fuller, C. J., Hurtig, M., and Cruz, A. (2010). The OARSI histopathology initiative - recommendations for histological assessments of osteoarthritis in the horse. Osteoarthritis Cartilage 18(Suppl. 3), S93-S105.

Mclure, S. W., Fisher, J., Conaghan, P. G., and Williams, S. (2012). Regional cartilage properties of three quadruped tibiofemoral joints used in musculoskeletal research studies. Proc. Inst. Mech. Eng. H 226, 652-656. doi: 10.1177/0954411912447158

Meeusen, E. N., Snibson, K. J., Hirst, S. J., and Bischof, R. J. (2009). Sheep as a model species for the study and treatment of human asthma and other respiratory diseases. Drug Discov. Today Dis. Model. 6, 101-106. doi: 10.1016/j.ddmod. 2009.12.002

Meng, X., Ziadlou, R., Grad, S., Alini, M., Wen, C., Lai, Y., et al. (2020). Animal models of osteochondral defect for testing biomaterials. Biochem Res. Int. 2020:9659412.

Messer, A. E., Chan, J., Daley, A., Copeland, O., Marston, S. B., and Connolly, D. J. (2017). Investigations into the sarcomeric protein and $\mathrm{Ca}(2+)$-regulation abnormalities underlying hypertrophic cardiomyopathy in cats (Felix catus). Front. Physiol. 8:348. doi: 10.3389/fphys.2017.00348

Meurs, K. M., Lahmers, S., Keene, B. W., White, S. N., Oyama, M. A., Mauceli, E., et al. (2012). A splice site mutation in a gene encoding for PDK4, a mitochondrial protein, is associated with the development of dilated cardiomyopathy in the Doberman pinscher. Hum. Genet. 131, 1319-1325. doi: 10.1007/s00439-012-1158-2

Meurs, K. M., Mauceli, E., Lahmers, S., Acland, G. M., White, S. N., and Lindblad-Toh, K. (2010). Genome-wide association identifies a deletion in the 3' untranslated region of striatin in a canine model of arrhythmogenic right ventricular cardiomyopathy. Hum. Genet. 128, 315-324. doi: 10.1007/s00439010-0855-y

Meurs, K. M., Norgard, M. M., Ederer, M. M., Hendrix, K. P., and Kittleson, M. D. (2007). A substitution mutation in the myosin binding protein $\mathrm{C}$ gene in ragdoll hypertrophic cardiomyopathy. Genomics 90, 261-264. doi: 10.1016/j.ygeno. 2007.04.007

Meurs, K. M., Sanchez, X., David, R. M., Bowles, N. E., Towbin, J. A., Reiser, P. J., et al. (2005). A cardiac myosin binding protein $\mathrm{C}$ mutation in the Maine Coon cat with familial hypertrophic cardiomyopathy. Hum. Mol. Genet. 14, 3587-3593. doi: 10.1093/hmg/ddi386

Meurs, K. M., Stern, J. A., Reina-Doreste, Y., Spier, A. W., Koplitz, S. L., and Baumwart, R. D. (2014). Natural history of arrhythmogenic right ventricular cardiomyopathy in the boxer dog: a prospective study. J. Vet. Intern. Med. 28, 1214-1220. doi: 10.1111 jvim. 12385

Mienaltowski, M. J., Dunkman, A. A., Buckley, M. R., Beason, D. P., Adams, S. M., Birk, D. E., et al. (2016). Injury response of geriatric mouse patellar tendons. J. Orthop. Res. 34, 1256-1263. doi: 10.1002/jor.23144

Milner, P. I., Clegg, P. D., and Stewart, M. C. (2011). Stem cell-based therapies for bone repair. Vet. Clin. North Am. Equine Pract. 27, 299-314.

Mitra, A., Leyes, A., Manser, K., Roadcap, B., Mestre, C., Tatosian, D., et al. (2015). Use of minipig skin biopsy model as an innovative tool to design topical formulation to achieve desired pharmacokinetics in humans. J. Pharm. Sci. 104, 1701-1708. doi: 10.1002/jps.24383

Moezzi, L., Pourfathollah, A. A., Alimoghaddam, K., Soleimani, M., and Ardjmand, A. R. (2005). The effect of cryopreservation on clonogenic capacity and in vitro expansion potential of umbilical cord blood progenitor cells. Transplant. Proc. 37, 4500-4503. doi: 10.1016/j.transproceed.2005.10.107

Moraes, J. R., Facco, G. G., Moraes, F. R., Engracia Filho, J. R., Miyazato, L. G., and Beretta, D. C. (2009). Effects of glycosaminoglycan polysulphate on the 
organisation of collagen fibres in experimentally induced tendonitis in horses. Vet. Rec. 165, 203-205. doi: 10.1136/vr.165.7.203

Moran, C. J., Ramesh, A., Brama, P. A., O’byrne, J. M., O’brien, F. J., and Levingstone, T. J. (2016). The benefits and limitations of animal models for translational research in cartilage repair. J. Exp. Orthop. 3:1.

Morris, M. W. Jr., Allukian, M. III, Herdrich, B. J., Caskey, R. C., Zgheib, C., $\mathrm{Xu}$, J., et al. (2014). Modulation of the inflammatory response by increasing fetal wound size or interleukin-10 overexpression determines wound phenotype and scar formation. Wound Repair Regen. 22, 406-414. doi: 10.1111/wrr. 12180

Morrison, J. L., Berry, M. J., Botting, K. J., Darby, J. R. T., Frasch, M. G., Gatford, K. L., et al. (2018). Improving pregnancy outcomes in humans through studies in sheep. Am. J. Physiol. Regul. Integr. Comp. Physiol. 315, R1123-R1153.

Mosqueira, D., Mannhardt, I., Bhagwan, J. R., Lis-Slimak, K., Katili, P., Scott, E., et al. (2018). CRISPR/Cas9 editing in human pluripotent stem cellcardiomyocytes highlights arrhythmias, hypocontractility, and energy depletion as potential therapeutic targets for hypertrophic cardiomyopathy. Eur. Heart J. 39, 3879-3892. doi: 10.1093/eurheartj/ehy249

Moss, T. J., Knox, C. L., Kallapur, S. G., Nitsos, I., Theodoropoulos, C., Newnham, J. P., et al. (2008). Experimental amniotic fluid infection in sheep: effects of Ureaplasma parvum serovars 3 and 6 on preterm or term fetal sheep. Am. J. Obstet. Gynecol. 198, 122.e1-122.e8. doi: 10.1016/j.ajog.2007.06.065

Muller, T., Feichtinger, H., Berger, H., and Muller, W. (1996). Endemic Tyrolean infantile cirrhosis: an ecogenetic disorder. Lancet 347, 877-880. doi: 10.1016/ s0140-6736(96)91351-3

Murayama, N., Kaneko, N., Horiuchi, K., Ohyama, K., Shimizu, M., Ito, K., et al. (2009). Cytochrome P450-dependent drug oxidation activity of liver microsomes from Microminipigs, a possible new animal model for humans in non-clinical studies. Drug Metab. Pharmacokinet. 24, 404-408. doi: 10.2133/ dmpk.24.404

Murphy, M. K., Arzi, B., Hu, J. C., and Athanasiou, K. A. (2013). Tensile characterization of porcine temporomandibular joint disc attachments. J. Dent. Res. 92, 753-758. doi: 10.1177/0022034513494817

Music, E., Futrega, K., and Doran, M. R. (2018). Sheep as a model for evaluating mesenchymal stem/stromal cell (Msc)-based chondral defect repair. Osteoarthritis Cartilage 26, 730-740. doi: 10.1016/j.joca.2018.03.006

Muttini, A., Russo, V., Rossi, E., Mattioli, M., Barboni, B., Tosi, U., et al. (2015). Pilot experimental study on amniotic epithelial mesenchymal cell transplantation in natural occurring tendinopathy in horses. Ultrasonographic and histological comparison. Muscles Ligaments Tendons J. 5, 5-11.

Nadal-Ginard, B., Kajstura, J., Leri, A., and Anversa, P. (2003). Myocyte death, growth, and regeneration in cardiac hypertrophy and failure. Circ. Res. 92, 139-150. doi: 10.1161/01.res.0000053618.86362.df

Namba, R. S., Meuli, M., Sullivan, K. M., Le, A. X., and Adzick, N. S. (1998). Spontaneous repair of superficial defects in articular cartilage in a fetal lamb model. J. Bone Joint Surg. Am. 80, 4-10. doi: 10.2106/00004623-19980100000003

Nelson, T. E. (1990). Porcine malignant hyperthermia: critical temperatures for in vivo and in vitro responses. Anesthesiology 73, 449-454. doi: 10.1097/ 00000542-199009000-00013

Newman, E., Turner, A. S., and Wark, J. D. (1995). The potential of sheep for the study of osteopenia: current status and comparison with other animal models. Bone 16, 277s-284s. doi: 10.1016/8756-3282(95)00026-a

Nitsos, I., Rees, S. M., Duncan, J., Kramer, B. W., Harding, R., Newnham, J. P., et al. (2006). Chronic exposure to intra-amniotic lipopolysaccharide affects the ovine fetal brain. J. Soc. Gynecol. Investig. 13, 239-247. doi: 10.1016/j.jsgi.2006. 02.011

Niu, D., Wei, H. J., Lin, L., George, H., Wang, T., Lee, I. H., et al. (2017). Inactivation of porcine endogenous retrovirus in pigs using CRISPR-Cas9. Science 357, 1303-1307. doi: 10.1126/science.aan4187

Nixon, A. J., Dahlgren, L. A., Haupt, J. L., Yeager, A. E., and Ward, D. L. (2008). Effect of adipose-derived nucleated cell fractions on tendon repair in horses with collagenase-induced tendinitis. Am. J. Vet. Res. 69, 928-937. doi: 10.2460/ ajvr.69.7.928

Oakley, S. P., Lassere, M. N., Portek, I., Szomor, Z., Ghosh, P., Kirkham, B. W., et al. (2004). Biomechanical, histologic and macroscopic assessment of articular cartilage in a sheep model of osteoarthritis. Osteoarthritis Cartilage 12, 667-679. doi: 10.1016/j.joca.2004.05.006
Okada, Y., Wu, D., Trynka, G., Raj, T., Terao, C., Ikari, K., et al. (2014). Genetics of rheumatoid arthritis contributes to biology and drug discovery. Nature 506, 376-381.

O'leary, S. A., Link, J. M., Klineberg, E. O., Hu, J. C., and Athanasiou, K. A. (2017). Characterization of facet joint cartilage properties in the human and interspecies comparisons. Acta Biomater. 54, 367-376. doi: 10.1016/j.actbio. 2017.03.017

Orsini, J. A. (2012). Supporting limb laminitis: the four important 'whys'. Equine Vet. J. 44, 741-745. doi: 10.1111/j.2042-3306.2012.00662.x

Pacini, S., Spinabella, S., Trombi, L., Fazzi, R., Galimberti, S., Dini, F., et al. (2007). Suspension of bone marrow-derived undifferentiated mesenchymal stromal cells for repair of superficial digital flexor tendon in race horses. Tissue Eng. 13, 2949-2955. doi: 10.1089/ten.2007.0108

Panettieri, R. A. Jr. (2016). Neutrophilic and Pauci-immune Phenotypes in Severe Asthma. Immunol. Allergy Clin. North Am. 36, 569-579. doi: 10.1016/j.iac.2016. 03.007

Parker, H. G., Shearin, A. L., and Ostrander, E. A. (2010). Man's best friend becomes biology's best in show: genome analyses in the domestic dog. Annu. Rev. Genet. 44, 309-336. doi: 10.1146/annurev-genet-102808-115200

Patterson-Kane, J. C., and Firth, E. C. (2009). The pathobiology of exercise-induced superficial digital flexor tendon injury in Thoroughbred racehorses. Vet. J. 181, 79-89. doi: 10.1016/j.tvjl.2008.02.009

Payne, J., Luis Fuentes, V., Boswood, A., Connolly, D., Koffas, H., and Brodbelt, D. (2010). Population characteristics and survival in 127 referred cats with hypertrophic cardiomyopathy (1997 to 2005). J. Small Anim. Pract. 51, 540-547. doi: 10.1111/j.1748-5827.2010.00989.x

Pearce, A. I., Richards, R. G., Milz, S., Schneider, E., and Pearce, S. G. (2007). Animal models for implant biomaterial research in bone: a review. Eur. Cell Mater. 13, 1-10. doi: 10.22203/ecm.v013a01

Pedersen, R., Andersen, A. D., Molbak, L., Stagsted, J., and Boye, M. (2013a). Changes in the gut microbiota of cloned and non-cloned control pigs during development of obesity: gut microbiota during development of obesity in cloned pigs. BMC Microbiol. 13:30. doi: 10.1186/1471-2180-13-30

Pedersen, R., Ingerslev, H. C., Sturek, M., Alloosh, M., Cirera, S., Christoffersen, B. O., et al. (2013b). Characterisation of gut microbiota in Ossabaw and Gottingen minipigs as models of obesity and metabolic syndrome. PLoS One 8:e56612. doi: 10.1371/journal.pone.0056612

Perleberg, C., Kind, A., and Schnieke, A. (2018). Genetically engineered pigs as models for human disease. Dis. Model. Mech. 11:dmm030783. doi: 10.1242/ dmm.030783

Petersen, B., Ramackers, W., Lucas-Hahn, A., Lemme, E., Hassel, P., Queisser, A. L., et al. (2011). Transgenic expression of human heme oxygenase-1 in pigs confers resistance against xenograft rejection during ex vivo perfusion of porcine kidneys. Xenotransplantation 18, 355-368. doi: 10.1111/j.1399-3089. 2011.00674.x

Phelps, C. J., Koike, C., Vaught, T. D., Boone, J., Wells, K. D., Chen, S. H., et al. (2003). Production of alpha 1,3-galactosyltransferase-deficient pigs. Science 299, 411-414. doi: 10.1126/science.1078942

Pinnapureddy, A. R., Stayner, C., Mcewan, J., Baddeley, O., Forman, J., and Eccles, M. R. (2015). Large animal models of rare genetic disorders: sheep as phenotypically relevant models of human genetic disease. Orphanet J. Rare Dis. 10:107.

Pobloth, A. M., Schell, H., Petersen, A., Beierlein, K., Kleber, C., Schmidt-Bleek, K., et al. (2018). Tubular open-porous beta-tricalcium phosphate polycaprolactone scaffolds as guiding structure for segmental bone defect regeneration in a novel sheep model. J. Tissue Eng. Regen. Med. 12, 897-911. doi: 10.1002/term.2446

Pogue, B., Estrada, A. H., Sosa-Samper, I., Maisenbacher, H. W., Lamb, K. E., Mincey, B. D., et al. (2013). Stem-cell therapy for dilated cardiomyopathy: a pilot study evaluating retrograde coronary venous delivery. J. Small Anim. Pract. 54, 361-366. doi: 10.1111/jsap.12098

Polejaeva, I. A., Rutigliano, H. M., and Wells, K. D. (2016). Livestock in biomedical research: history, current status and future prospective. Reprod. Fertil. Dev. 28, $112-124$.

Pond, M. J., and Nuki, G. (1973). Experimentally-induced osteoarthritis in the dog. Ann. Rheum. Dis. 32, 387-388. doi: 10.1136/ard.32.4.387

Poole, R., Blake, S., Buschmann, M., Goldring, S., Laverty, S., Lockwood, S., et al. (2010). Recommendations for the use of preclinical models in the study and treatment of osteoarthritis. Osteoarthritis Cartilage 18(Suppl. 3), S10-S16. 
Porada, C. D., Park, P. J., Almeida-Porada, G., Liu, W., Ozturk, F., Glimp, H. A., et al. (2005). Gestational age of recipient determines pattern and level of transgene expression following in utero retroviral gene transfer. Mol. Ther. 11, 284-293. doi: 10.1016/j.ymthe.2004.09.009

Prabhakar, S. (2012). Translational research challenges: finding the right animal models. J. Investig. Med. 60, 1141-1146. doi: 10.2310/jim.0b013e318271fb3b

Price, J., Catriona, S., Welsh, E. M., and Waran, N. K. (2003). Preliminary evaluation of a behaviour-based system for assessment of post-operative pain in horses following arthroscopic surgery. Vet. Anaesth. Analg. 30, 124-137. doi: 10.1046/j.1467-2995.2003.00139.x

Proffen, B. L., Mcelfresh, M., Fleming, B. C., and Murray, M. M. (2012). A comparative anatomical study of the human knee and six animal species. Knee 19, 493-499. doi: 10.1016/j.knee.2011.07.005

Provost, P. J. (2019). “Wound healing”, in Equine Surgery, 5th Edn, eds J. A. Auer, J. A. Stick, J. M. Kümmerle, and T. Prang (Amsterdam: Elsevier).

Rabbani, S., Soleimani, M., Sahebjam, M., Imani, M., Nassiri, S. M., Atashi, A., et al. (2017). Effects of endothelial and mesenchymal stem cells on improving myocardial function in a sheep animal model. J. Tehran Heart Cent. 12, 65-71.

Radtke, C., Allmeling, C., Waldmann, K. H., Reimers, K., Thies, K., Schenk, H. C., et al. (2011). Spider silk constructs enhance axonal regeneration and remyelination in long nerve defects in sheep. PLoS One 6:e16990. doi: 10.1371/ journal.pone.0016990

Renzi, S., Ricco, S., Dotti, S., Sesso, L., Grolli, S., Cornali, M., et al. (2013). Autologous bone marrow mesenchymal stromal cells for regeneration of injured equine ligaments and tendons: a clinical report. Res. Vet. Sci. 95, 272-277. doi: 10.1016/j.rvsc.2013.01.017

Richardson, L. E., Dudhia, J., Clegg, P. D., and Smith, R. (2007). Stem cells in veterinary medicine-attempts at regenerating equine tendon after injury. Trends Biotechnol. 25, 409-416. doi: 10.1016/j.tibtech.2007.07.009

Ripoll Vera, T., Monserrat Iglesias, L., Hermida Prieto, M., Ortiz, M., Rodriguez Garcia, I., and Govea Callizo, N. (2010). The R820W mutation in the MYBPC3 gene, associated with hypertrophic cardiomyopathy in cats, causes hypertrophic cardiomyopathy and left ventricular non-compaction in humans. Int. J. Cardiol. 145, 405-407. doi: 10.1016/j.ijcard.2010.04.032

Robinson, P., Liu, X., Sparrow, A., Patel, S., Zhang, Y. H., Casadei, B., et al. (2018). Hypertrophic cardiomyopathy mutations increase myofilament $\mathrm{Ca}(2+)$ buffering, alter intracellular $\mathrm{Ca}(2+)$ handling, and stimulate $\mathrm{Ca}(2+)$-dependent signaling. J. Biol. Chem. 293, 10487-10499. doi: 10.1074/jbc.ra118.002081

Rogers, C. S. (2016). Genetically engineered livestock for biomedical models. Transgenic Res. 25, 345-359. doi: 10.1007/s11248-016-9928-6

Rolauffs, B., Williams, J. M., Aurich, M., Grodzinsky, A. J., Kuettner, K. E., and Cole, A. A. (2010). Proliferative remodeling of the spatial organization of human superficial chondrocytes distant from focal early osteoarthritis. Arthritis Rheum. 62, 489-498.

Sachs, D. H., Sykes, M., and Yamada, K. (2009). Achieving tolerance in pig-toprimate xenotransplantation: reality or fantasy. Transpl. Immunol. 21, 101-105. doi: 10.1016/j.trim.2008.11.005

Sanjurjo-Rodriguez, C., Castro-Vinuelas, R., Hermida-Gomez, T., FernandezVazquez, T., Fuentes-Boquete, I. M., De Toro-Santos, F. J., et al. (2017). Ovine mesenchymal stromal cells: morphologic, phenotypic and functional characterization for osteochondral tissue engineering. PLoS One 12:e171231. doi: 10.1371/journal.pone.0171231

Sanz-Ramos, P., Duart, J., Rodriguez-Goni, M. V., Vicente-Pascual, M., Dotor, J., Mora, G., et al. (2014). Improved chondrogenic capacity of collagen hydrogelexpanded chondrocytes: in vitro and in vivo analyses. J. Bone Joint Surg. Am. 96, 1109-1117. doi: 10.2106/jbjs.m.00271

Sasaki-Honda, M., Jonouchi, T., Arai, M., Hotta, A., Mitsuhashi, S., Nishino, I., et al. (2018). A patient-derived iPSC model revealed oxidative stress increases facioscapulohumeral muscular dystrophy-causative DUX4. Hum. Mol. Genet. 27, 4024-4035. doi: 10.1093/hmg/ddy293

Sawyer, M., Moe, J., and Osburn, B. I. (1978). Ontogeny of immunity and leukocytes in the ovine fetus and elevation of immunoglobulins related to congenital infection. Am. J. Vet. Res. 39, 643-648.

Schagemann, J. C., Erggelet, C., Chung, H. W., Lahm, A., Kurz, H., and Mrosek, E. H. (2009). Cell-laden and cell-free biopolymer hydrogel for the treatment of osteochondral defects in a sheep model. Tissue Eng. Part A 15, 75-82. doi: 10.1089/ten.tea.2008.0087
Scharf, A., Holmes, S. P., Thoresen, M., Mumaw, J., Stumpf, A., and Peroni, J. (2016). MRI-based assessment of intralesional delivery of bone marrowderived mesenchymal stem cells in a model of equine tendonitis. Stem Cells Int. 2016:8610964.

Scheerlinck, J. P., Snibson, K. J., Bowles, V. M., and Sutton, P. (2008). Biomedical applications of sheep models: from asthma to vaccines. Trends Biotechnol. 26, 259-266. doi: 10.1016/j.tibtech.2008.02.002

Scheinberg, I. H., and Sternlieb, I. (1996). Wilson disease and idiopathic copper toxicosis. Am. J. Clin. Nutr. 63, 842s-845s.

Schnabel, L. V., Lynch, M. E., Van Der Meulen, M. C., Yeager, A. E., Kornatowski, M. A., and Nixon, A. J. (2009). Mesenchymal stem cells and insulin-like growth factor-I gene-enhanced mesenchymal stem cells improve structural aspects of healing in equine flexor digitorum superficialis tendons. J. Orthop. Res. 27, 1392-1398. doi: 10.1002/jor.20887

Schnabel, L. V., Mohammed, H. O., Miller, B. J., Mcdermott, W. G., Jacobson, M. S., Santangelo, K. S., et al. (2007). Platelet rich plasma (PRP) enhances anabolic gene expression patterns in flexor digitorum superficialis tendons. J. Orthop. Res. 25, 230-240. doi: 10.1002/jor.20278

Schramme, M., Hunter, S., Campbell, N., Blikslager, A., and Smith, R. (2010). A surgical tendonitis model in horses: technique, clinical, ultrasonographic and histological characterisation. Vet. Comp. Orthop. Traumatol. 23, 231-239.

Segatto, N. V., Remiao, M. H., Schachtschneider, K. M., Seixas, F. K., Schook, L. B., and Collares, T. (2017). The oncopig cancer model as a complementary tool for phenotypic drug discovery. Front. Pharmacol. 8:894. doi: 10.3389/fphar.2017. 00894

Semsarian, C., Ingles, J., Maron, M. S., and Maron, B. J. (2015). New perspectives on the prevalence of hypertrophic cardiomyopathy. J. Am. Coll. Cardiol. 65, 1249-1254.

Seo, J. P., Tsuzuki, N., Haneda, S., Yamada, K., Furuoka, H., Tabata, Y., et al. (2014). Osteoinductivity of gelatin/beta-tricalcium phosphate sponges loaded with different concentrations of mesenchymal stem cells and bone morphogenetic protein-2 in an equine bone defect model. Vet. Res. Commun. 38, 73-80. doi: 10.1007/s11259-013-9587-5

Shanks, N., Greek, R., and Greek, J. (2009). Are animal models predictive for humans? Philos. Ethics Humanit. Med. 4:2.

Shapiro, S. D. (2008). The use of transgenic mice for modeling airways disease. Pulm. Pharmacol. Ther. 21, 699-701. doi: 10.1016/j.pupt.2008.01.006

Sheehan, A., Messer, A. E., Papadaki, M., Choudhry, A., Kren, V., Biedermann, D., et al. (2018). Molecular defects in cardiac Myofilament $\mathrm{Ca}(2+)$-regulation due to cardiomyopathy-linked mutations can be reversed by small molecules binding to troponin. Front. Physiol. 9:243. doi: 10.3389/fphys.2018.00243

Shinagawa, K., and Kojima, M. (2003). Mouse model of airway remodeling: strain differences. Am. J. Respir. Crit. Care Med. 168, 959-967. doi: 10.1164/rccm. 200210-1188oc

Silverstein, A. M., Prendergast, R. A., and Kraner, K. L. (1964). Fetal response to antigenic stimulus. IV. Rejection of skin homografts by the fetal lamb. J. Exp. Med. 119, 955-964. doi: 10.1084/jem.119.6.955

Silverstein, A. M., Uhr, J. W., Kraner, K. L., and Lukes, R. J. (1963). Fetal response to antigenic stimulus. Ii. Antibody production by the fetal lamb. J. Exp. Med. 117, 799-812. doi: 10.1084/jem.117.5.799

Simoes, I. N., Vale, P., Soker, S., Atala, A., Keller, D., Noiva, R., et al. (2017). Acellular urethra bioscaffold: decellularization of whole urethras for tissue engineering applications. Sci. Rep. 7:41934.

Simpson, S., Edwards, J., Emes, R. D., Cobb, M. A., Mongan, N. P., and Rutland, C. S. (2015a). A predictive model for canine dilated cardiomyopathy-a metaanalysis of Doberman Pinscher data. PeerJ 3:e842. doi: 10.7717/peerj.842

Simpson, S., Edwards, J., Ferguson-Mignan, T. F., Cobb, M., Mongan, N. P., and Rutland, C. S. (2015b). Genetics of human and canine dilated cardiomyopathy. Int. J. Genomics 2015:204823.

Skaanild, M. T. (2006). Porcine cytochrome P450 and metabolism. Curr. Pharm. Des. 12, 1421-1427. doi: 10.2174/138161206776361183

Smith, R., Mcilwraith, W., Schweitzer, R., Kadler, K., Cook, J., Caterson, B., et al. (2014). Advances in the understanding of tendinopathies: a report on the Second Havemeyer Workshop on equine tendon disease. Equine Vet. J. 46, 4-9. doi: $10.1111 /$ evj.12128

Smith, R. K. (2008). Mesenchymal stem cell therapy for equine tendinopathy. Disabil. Rehabil. 30, 1752-1758. doi: 10.1080/09638280701788241 
Smith, R. K., Korda, M., Blunn, G. W., and Goodship, A. E. (2003). Isolation and implantation of autologous equine mesenchymal stem cells from bone marrow into the superficial digital flexor tendon as a potential novel treatment. Equine Vet. J. 35, 99-102. doi: 10.2746/042516403775467388

Smith, R. K., Werling, N. J., Dakin, S. G., Alam, R., Goodship, A. E., and Dudhia, J. (2013). Beneficial effects of autologous bone marrow-derived mesenchymal stem cells in naturally occurring tendinopathy. PLoS One 8:e75697. doi: 10. 1371/journal.pone.0075697

Sole, A., Spriet, M., Galuppo, L. D., Padgett, K. A., Borjesson, D. L., Wisner, E. R., et al. (2012). Scintigraphic evaluation of intra-arterial and intravenous regional limb perfusion of allogeneic bone marrow-derived mesenchymal stem cells in the normal equine distal limb using (99m) Tc-HMPAO. Equine Vet. J. 44, 594-599. doi: 10.1111/j.2042-3306.2011.00530.x

Sole, A., Spriet, M., Padgett, K. A., Vaughan, B., Galuppo, L. D., Borjesson, D. L., et al. (2013). Distribution and persistence of technetium-99 hexamethyl propylene amine oxime-labelled bone marrow-derived mesenchymal stem cells in experimentally induced tendon lesions after intratendinous injection and regional perfusion of the equine distal limb. Equine Vet. J. 45, 726-731. doi: 10.1111/evj.12063

Song, F., Tang, J., Geng, R., Hu, H., Zhu, C., Cui, W., et al. (2014). Comparison of the efficacy of bone marrow mononuclear cells and bone mesenchymal stem cells in the treatment of osteoarthritis in a sheep model. Int. J. Clin. Exp. Pathol. 7, 1415-1426.

Song, W., Vikhorev, P. G., Kashyap, M. N., Rowlands, C., Ferenczi, M. A., Woledge, R. C., et al. (2013). Mechanical and energetic properties of papillary muscle from ACTC E99K transgenic mouse models of hypertrophic cardiomyopathy. Am. J. Physiol. Heart Circ. Physiol. 304, H1513-H1524.

Spetzler, V. N., Goldaracena, N., Knaak, J. M., Louis, K. S., Selzner, N., and Selzner, M. (2015). Technique of porcine liver procurement and orthotopic transplantation using an active porto-caval shunt. J. Vis. Exp. 99:e52055.

Spriet, M., Buerchler, S., Trela, J. M., Hembrooke, T. A., Padgett, K. A., Rick, M. C., et al. (2015). Scintigraphic tracking of mesenchymal stem cells after intravenous regional limb perfusion and subcutaneous administration in the standing horse. Vet. Surg. 44, 273-280. doi: 10.1111/j.1532-950x.2014.12289.x

Starritt, N. E., Kettle, S. A., and Glasby, M. A. (2011). Sutureless repair of the facial nerve using biodegradable glass fabric. Laryngoscope 121, 1614-1619. doi: 10.1002/lary.21868

Stramer, B. M., Mori, R., and Martin, P. (2007). The inflammation-fibrosis link? A Jekyll and Hyde role for blood cells during wound repair. J. Invest. Dermatol. 127, 1009-1017. doi: 10.1038/sj.jid.5700811

Stuehler, B., Reichert, J., Stremmel, W., and Schaefer, M. (2004). Analysis of the human homologue of the canine copper toxicosis gene Murr1 in Wilson disease patients. J. Mol. Med. 82, 629-634.

Sullivan, D. C., Mirmalek-Sani, S. H., Deegan, D. B., Baptista, P. M., Aboushwareb, T., Atala, A., et al. (2012). Decellularization methods of porcine kidneys for whole organ engineering using a high-throughput system. Biomaterials 33, 7756-7764. doi: 10.1016/j.biomaterials.2012.07.023

Sweigart, M. A., Zhu, C. F., Burt, D. M., Deholl, P. D., Agrawal, C. M., Clanton, T. O., et al. (2004). Intraspecies and interspecies comparison of the compressive properties of the medial meniscus. Ann. Biomed. Eng. 32, 1569-1579. doi: 10.1114/b:abme.0000049040.70767.5c

Swindle, M. M. (2007). Swine in the Laboratory: Surgery, Anesthesia, Imaging, and Experimental Techniques, 2nd Edn. Boca Raton, FL: CRC Press.

Swindle, M. M., Makin, A., Herron, A. J., Clubb, F. J. Jr., and Frazier, K. S. (2012). Swine as models in biomedical research and toxicology testing. Vet. Pathol. 49, 344-356. doi: 10.1177/0300985811402846

Tankersley, C. G., Fitzgerald, R. S., and Kleeberger, S. R. (1994). Differential control of ventilation among inbred strains of mice. Am. J. Physiol. 267, R1371-R1377.

Tanner, M. S. (1998). Role of copper in Indian childhood cirrhosis. Am. J. Clin. Nutr. 67, 1074s-1081s. doi: 10.1093/ajcn/67.5.1074s

Taylor, W. R., Ehrig, R. M., Heller, M. O., Schell, H., Seebeck, P., and Duda, G. N. (2006). Tibio-femoral joint contact forces in sheep. J. Biomech. 39, 791-798. doi: 10.1016/j.jbiomech.2005.02.006

Teeple, E., Jay, G. D., Elsaid, K. A., and Fleming, B. C. (2013). Animal models of osteoarthritis: challenges of model selection and analysis. AAPS J. 15, 438-446. doi: 10.1208/s12248-013-9454-x

Tellegen, A. R., Dessing, A. J., Houben, K., Riemers, F. M., Creemers, L. B., Mastbergen, S. C., et al. (2019). Dog as a model for osteoarthritis: the fgf4 retrogene insertion may matter. J. Orthop. Res. 37, 2550-2560. doi: 10.1002/ jor. 24432

Tellegen, A. R., Rudnik-Jansen, I., Beukers, M., Miranda-Bedate, A., Bach, F. C., De Jong, W., et al. (2018). Intradiscal delivery of celecoxib-loaded microspheres restores intervertebral disc integrity in a preclinical canine model. J. Control. Release 286, 439-450. doi: 10.1016/j.jconrel.2018.08.019

Thornburg, L. P. (1998). Histomorphological and immunohistochemical studies of chronic active hepatitis in Doberman Pinschers. Vet. Pathol. 35, 380-385. doi: 10.1177/030098589803500507

Thornburg, L. P., Rottinghaus, G., Dennis, G., and Crawford, S. (1996). The relationship between hepatic copper content and morphologic changes in the liver of West Highland White Terriers. Vet. Pathol. 33, 656-661. doi: 10.1177/ 030098589603300604

Thorpe, C. T., Clegg, P. D., and Birch, H. L. (2010). A review of tendon injury: why is the equine superficial digital flexor tendon most at risk? Equine Vet. J. 42, 174-180. doi: 10.2746/042516409x480395

Tidholm, A., and Jonsson, L. (2005). Histologic characterization of canine dilated cardiomyopathy. Vet. Pathol. 42, 1-8. doi: 10.1354/vp.42-1-1

Tompkins, D., Hudgens, E., Horohov, D., and Baldwin, C. L. (2010). Expressed gene sequences of the equine cytokines interleukin-17 and interleukin-23. Vet. Immunol. Immunopathol. 133, 309-313. doi: 10.1016/j.vetimm.2009.08.008

Trela, J. M., Spriet, M., Padgett, K. A., Galuppo, L. D., Vaughan, B., and Vidal, M. A. (2014). Scintigraphic comparison of intra-arterial injection and distal intravenous regional limb perfusion for administration of mesenchymal stem cells to the equine foot. Equine Vet. J. 46, 479-483. doi: 10.1111/evj.12137

Twedt, D. C., Sternlieb, I., and Gilbertson, S. R. (1979). Clinical, morphologic, and chemical studies on copper toxicosis of Bedlington Terriers. J. Am. Vet. Med. Assoc. 175, 269-275.

Tytherleigh-Strong, G., Hurtig, M., and Miniaci, A. (2005). Intra-articular hyaluronan following autogenous osteochondral grafting of the knee. Arthroscopy 21, 999-1005. doi: 10.1016/j.arthro.2005.05.001

Van De Sluis, B., Rothuizen, J., Pearson, P. L., Van Oost, B. A., and Wijmenga, C. (2002). Identification of a new copper metabolism gene by positional cloning in a purebred dog population. Hum. Mol. Genet. 11, 165-173. doi: 10.1093/hmg/ 11.2.165

Van De Sluis, B. J., Breen, M., Nanji, M., Van Wolferen, M., De Jong, P., Binns, M. M., et al. (1999). Genetic mapping of the copper toxicosis locus in Bedlington terriers to dog chromosome 10 , in a region syntenic to human chromosome region 2p13-p16. Hum. Mol. Genet. 8, 501-507. doi: 10.1093/hmg/8.3.501

Van Loon, V. J., Scheffer, C. J., Genn, H. J., Hoogendoorn, A. C., and Greve, J. W. (2014). Clinical follow-up of horses treated with allogeneic equine mesenchymal stem cells derived from umbilical cord blood for different tendon and ligament disorders. Vet. Q. 34, 92-97. doi: 10.1080/01652176.2014.949390

Van Steenbeek, F. G., Hytonen, M. K., Leegwater, P. A., and Lohi, H. (2016). The canine era: the rise of a biomedical model. Anim. Genet. 47, 519-527. doi: 10.1111/age. 12460

Van Weeren, P. R., and Back, W. (2016). Musculoskeletal disease in aged horses and its management. Vet. Clin. North Am. Equine Pract. 32, 229-247. doi: 10.1016/j.cveq.2016.04.003

Vandeweerd, J. M., Hontoir, F., Kirschvink, N., Clegg, P., Nisolle, J. F., Antoine, N., et al. (2013). Prevalence of naturally occurring cartilage defects in the ovine knee. Osteoarthritis Cartilage 21, 1125-1131. doi: 10.1016/j.joca.2013. 05.006

Varcoe, T. J., Gatfort, K. L., Holman, S. L., Cheung, P., Berry, M. J., Wiese, M. D., et al. (2019). Considerations in selecting postoperative analgesia for pregnant sheep following fetal instrumentation surgery. Anim. Front. 9, 60-67. doi: 10.1093/af/vfz019

Vila, J., Pariaut, R., Moise, N. S., Oxford, E. M., Fox, P. R., Reynolds, C. A., et al. (2017). Structural and molecular pathology of the atrium in boxer arrhythmogenic right ventricular cardiomyopathy. J. Vet. Cardiol. 19, 57-67. doi: 10.1016/j.jvc.2016.09.001

Vincent, T. L., Williams, R. O., Maciewicz, R., Silman, A., and Garside, P. (2012). Mapping pathogenesis of arthritis through small animal models. Rheumatology 51, 1931-1941. doi: 10.1093/rheumatology/kes035

Vischer, A. S., Connolly, D. J., Coats, C. J., Fuentes, V. L., Mckenna, W. J., Castelletti, S., et al. (2017). Arrhythmogenic right ventricular cardiomyopathy in Boxer dogs: the diagnosis as a link to the human disease. Acta Myol. 36, $135-150$. 
Vogel, T., Brockmann, J. G., Pigott, D., Neil, D. A. H., Muthusamy, A. S. R., Coussios, C. C., et al. (2017). Successful transplantation of porcine liver grafts following 48-hour normothermic preservation. PLoS One 12:e0188494. doi: 10.1371/journal.pone.0188494

Voleti, P. B., Buckley, M. R., and Soslowsky, L. J. (2012). Tendon healing: repair and regeneration. Annu. Rev. Biomed. Eng. 14, 47-71.

Vonk, W. I., De Bie, P., Wichers, C. G., Van Den Berghe, P. V., Van Der Plaats, R., Berger, R., et al. (2012). The copper-transporting capacity of ATP7A mutants associated with Menkes disease is ameliorated by COMMD1 as a result of improved protein expression. Cell. Mol. Life Sci. 69, 149-163. doi: 10.1007/ s00018-011-0743-1

Warnock, J. J., Fox, D. B., Stoker, A. M., Beatty, M., Cockrell, M., Janicek, J. C., et al. (2014). Culture of equine fibroblast-like synoviocytes on synthetic tissue scaffolds towards meniscal tissue engineering: a preliminary cell-seeding study. PeerJ 2:e353. doi: 10.7717/peerj.353

Watanabe, M., Li, H., Kim, A. G., Weilerstein, A., Radu, A., Davey, M., et al. (2016). Complete tissue coverage achieved by scaffold-based tissue engineering in the fetal sheep model of Myelomeningocele. Biomaterials 76, 133-143. doi: 10.1016/j.biomaterials.2015.10.051

Watts, A. E., Nixon, A. J., Yeager, A. E., and Mohammed, H. O. (2012). A collagenase gel/physical defect model for controlled induction of superficial digital flexor tendonitis. Equine Vet. J. 44, 576-586. doi: 10.1111/j.2042-3306. 2011.00471.x

Watts, A. E., Yeager, A. E., Kopyov, O. V., and Nixon, A. J. (2011). Fetal derived embryonic-like stem cells improve healing in a large animal flexor tendonitis model. Stem Cell Res. Ther. 2:4. doi: 10.1186/scrt45

Webb, C. B., Twedt, D. C., and Meyer, D. J. (2002). Copper-associated liver disease in Dalmatians: a review of 10 dogs (1998-2001). J. Vet. Intern. Med. 16, 665-668. doi: 10.1111/j.1939-1676.2002.tb02405.x

Wess, G., Schulze, A., Butz, V., Simak, J., Killich, M., Keller, L. J., et al. (2010). Prevalence of dilated cardiomyopathy in Doberman Pinschers in various age groups. J. Vet. Intern. Med. 24, 533-538. doi: 10.1111/j.1939-1676.2010.0479.x

Whitehouse, M. R., Howells, N. R., Parry, M. C., Austin, E., Kafienah, W., Brady, K., et al. (2017). Repair of torn avascular meniscal cartilage using undifferentiated autologous mesenchymal stem cells: from in vitro optimization to a first-inhuman study. Stem Cells Transl. Med. 6, 1237-1248. doi: 10.1002/sctm.160199

Williams, I. F., Mccullagh, K. G., Goodship, A. E., and Silver, I. A. (1984). Studies on the pathogenesis of equine tendonitis following collagenase injury. Res. Vet. Sci. 36, 326-338. doi: 10.1016/s0034-5288(18)31954-4

Williams, K., and Roman, J. (2016). Studying human respiratory disease in animals-role of induced and naturally occurring models. J. Pathol. 238, 220232. doi: $10.1002 /$ path.4658

Woodruff, P. G., Modrek, B., Choy, D. F., Jia, G., Abbas, A. R., Ellwanger, A., et al. (2009). T-helper type 2-driven inflammation defines major subphenotypes of asthma. Am. J. Respir. Crit. Care Med. 180, 388-395. doi: 10.1164/rccm.20090303920 c

Wu, Z. Y., Zhao, G. X., Chen, W. J., Wang, N., Wan, B., Lin, M. T., et al. (2006). Mutation analysis of 218 Chinese patients with Wilson disease revealed no correlation between the canine copper toxicosis gene Murr1 and Wilson disease. J. Mol. Med. 84, 438-442. doi: 10.1007/s00109-0050036-y

Xerogeanes, J. W., Fox, R. J., Takeda, Y., Kim, H. S., Ishibashi, Y., Carlin, G. J., et al. (1998). A functional comparison of animal anterior cruciate ligament models to the human anterior cruciate ligament. Ann. Biomed. Eng. 26, 345-352.

Yamamoto, S., Karashima, M., Sano, N., Fukushi, C., Tohyama, K., Arai, Y., et al. (2017). Utility of gottingen minipigs for prediction of human pharmacokinetic profiles after dermal drug application. Pharm. Res. 34, 2415-2424. doi: 10.1007/ s11095-017-2247-7

Yang, H., Wang, G., Sun, H., Shu, R., Liu, T., Wang, C. E., et al. (2014). Speciesdependent neuropathology in transgenic SOD1 pigs. Cell Res. 24, 464-481. doi: 10.1038/cr.2014.25

Yao, J., Huang, J., and Zhao, J. (2016). Genome editing revolutionize the creation of genetically modified pigs for modeling human diseases. Hum. Genet. 135, 1093-1105. doi: 10.1007/s00439-016-1710-6

Yu, H., Adesida, A. B., and Jomha, N. M. (2015). Meniscus repair using mesenchymal stem cells - a comprehensive review. Stem Cell Res. Ther. 6:86.

Zhao, W., Wang, Y., Liu, S., Huang, J., Zhai, Z., He, C., et al. (2015). The dynamic distribution of porcine microbiota across different ages and gastrointestinal tract segments. PLoS One 10:e0117441. doi: 10.1371/journal.pone.01 17441

Zorzi, A. R., Amstalden, E. M., Plepis, A. M., Martins, V. C., Ferretti, M., Antonioli, E., et al. (2015). Effect of human adipose tissue mesenchymal stem cells on the regeneration of ovine articular cartilage. Int. J. Mol. Sci. 16, 26813-26831. doi: 10.3390/ijms161125989

Zosky, G. R., and Sly, P. D. (2007). Animal models of asthma. Clin. Exp. Allergy 37, 973-988.

Conflict of Interest: The authors declare that the research was conducted in the absence of any commercial or financial relationships that could be construed as a potential conflict of interest.

Copyright (C) 2020 Ribitsch, Baptista, Lange-Consiglio, Melotti, Patruno, Jenner, Schnabl-Feichter, Dutton, Connolly, van Steenbeek, Dudhia and Penning. This is an open-access article distributed under the terms of the Creative Commons Attribution License (CC BY). The use, distribution or reproduction in other forums is permitted, provided the original author(s) and the copyright owner(s) are credited and that the original publication in this journal is cited, in accordance with accepted academic practice. No use, distribution or reproduction is permitted which does not comply with these terms. 